\title{
-
}

\section{Uncertainties in mass balance estimation of the Antarctic Ice Sheet using the input-output method}

Yijing $\operatorname{Lin}^{1,2^{*}}$, Yan Liu ${ }^{1,3^{*}}$, Zhitong Yu $\uparrow$, Xiao Cheng ${ }^{1,3,4}$, Qiang Shen ${ }^{5}$, Liyun Zhao ${ }^{1,3}$

${ }^{1}$ College of Global Change and Earth System Science (GCESS), Beijing Normal University, Beijing 100875, China \& South ern Marine Science and Engineering Guangdong Laboratory (Zhuhai), Zhuhai 519082, China;

${ }^{2}$ Qian Xuesen Laboratory of Space Technology, China Academy of Space Technology, Beijing 100094, China;

${ }^{3}$ Southern Marine Science and Engineering Guangdong Laboratory, Zhuhai 519082, China

${ }^{4}$ School of Geospatial Engineering and Science, Sun Yat-Sen University, Zhuhai 519082, China

${ }^{5}$ State Key Laboratory of Geodesy and Earth's Dynamics, Innovation Academy for Precision Measurement Science and Technology, CAS, Wuhan 430077, China;

*These authors contributed equally to this work.

† Correspondence to: Z. Yu (yuzhitong@qxslab.cn)

Abstract. The input-output method (IOM) is one of the most popular methods of estimating the ice sheet mass balance (MB), with a significant advantage in presenting the dynamics response of ice to climate change. Assessing the uncertainties of the

MB estimation using the IOM is crucial to gaining a clear understanding of the Antarctic ice-sheet mass budget. Here, we introduce a framework for assessing the uncertainties in the MB estimation due to the methodological differences in the IOM, the impact of the parameterization and scale effect on the modeled surface mass balance (SMB, input), and the impact of the uncertainties of ice thickness, ice velocity, and grounding line data on ice discharge (D, output). For the uncertainty assessment

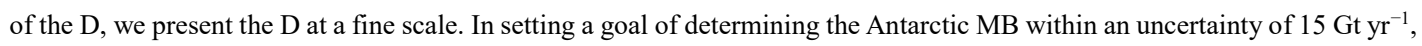
we found that the different strategies employed in the methods cause considerable uncertainties in the annual MB estimation. The uncertainty of the RACMO2.3 SMB caused by its parameterization can reach $20.4 \mathrm{Gt} \mathrm{yr}^{-1}$, while that due to the scale

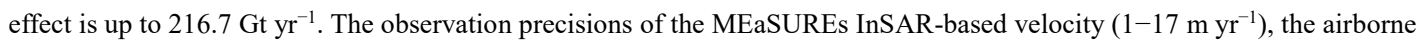
radio-echo sounder thickness $( \pm 100 \mathrm{~m})$, and the MEaSUREs InSAR-based grounding line $( \pm 100 \mathrm{~m})$ contribute uncertainties of $17.1 \mathrm{Gt} \mathrm{yr}^{-1}, 10.5 \pm 2.7 \mathrm{Gt} \mathrm{yr}^{-1}$ and $8.0 \sim 27.8 \mathrm{Gt} \mathrm{yr}^{-1}$ to the $\mathrm{D}$, respectively. However, the D uncertainty due to the remarkable ice thickness data gap, which is represented by the thickness difference between the BEDMAP2 and the BedMachine reaches 101.7 $\mathrm{Gt} \mathrm{yr}^{-1}$, which indicates that it is the dominant cause of the future D uncertainty. In addition, the interannual variability of the D caused by the annual changes in the ice velocity and ice thickness are considerable compared with the target

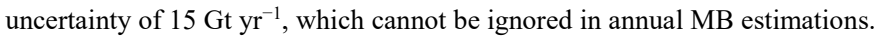


https://doi.org/10.5194/tc-2021-325

Preprint. Discussion started: 20 December 2021

(c) Author(s) 2021. CC BY 4.0 License.

\section{Introduction}

The Antarctic ice sheet (AIS) contains $88 \%$ of the global land ice, with a sea level equivalent of $58.3 \mathrm{~m}$ (Bamber et al., 2018), making it the largest potential source of future sea level rise and the most uncertain contributor to future sea level projections (Oppenheimer et al., 2019). As an important indicator of global climate change, even minor changes in the Antarctic ice volume have significant impacts not only on the global mean sea level but also on the hydrological cycle, carbon cycle, atmospheric circulation, sea surface temperature, sea salinity, and thermohaline circulation (Thomas et al., 2017; Wadham et al., 2019; Smith et al., 2020). For decades, estimating the Antarctic mass balance (MB) and understanding how, where, and why the ice sheets lose mass have been the main goals of Antarctic research (Kennicutt et al., 2014). The need for a more accurate determination of the Antarctic mass budget has become imperative for gaining a better understanding of its dynamics, for improving our understanding of ice sheet evolution, and for enabling more accurate future projections of the global sea level (Shen et al., 2018). However, there is still a large uncertainty in the assessment of the ice sheet MB, and there are significant differences among the most recent results obtained using different methods due to the limitations of the methods used and the lack of data sources (Shepherd et al., 2018; Rignot et al., 2019; Smith et al., 2020; Hugonnet et al., 2021; Wang et al., 2021). A detailed understanding of the uncertainty sources is conducive to accurately estimating the ice sheet MB and to decreasing the uncertainties in the ice sheet's contribution to sea-level rise and determining its influencing mechanism (Massom and Lubin, 2006).

The four main methods for estimating the MB of ice sheets, based on different types of satellite observations include satellite altimetry (Helm et al., 2014; McMillan et al., 2014; Zwally et al., 2015; Smith et al., 2020), gravimetry (Velicogna et al., 2014; Forsberg et al., 2017), the input-output method (IOM) (Rignot et al., 2008; Rignot et al., 2011a; Rignot et al., 2019), and the reconciled estimate (Shepherd et al., 2012; Shepherd et al., 2018). As a unique method that can determine the physical processes responsible for mass loss, the IOM is the most advantageous for understanding the mass changes in each basin. It quantifies the glacier mass gained through snowfall and the loss via sublimation, meltwater runoff, and ice discharge into the ocean, allowing us to separately examine the changes in the surface mass balance (SMB) and ice dynamics on the scale of individual glacier drainage basins.

However, the IOM involves numerous parameters and complicated calculations, whose uncertainties result in large differences in the mass balance estimates (Bamber et al., 2018). In addition to the large uncertainty of up to three times those of altimetry and gravimetry, IOM estimates have a greater bias from the average result, which requires a more detailed analysis of the source of the differences to clarify whether this bias is significant or systematic (Shepherd et al., 2018). In particular, while the West Antarctic Ice Sheet (WAIS) and the Antarctic Peninsula Ice Sheet (APIS) are consistently thought to be in a state of continuous mass loss, whether the East Antarctic Ice Sheet (EAIS) is losing or gaining mass is still controversial. For the EAIS, in contrast to the mass gain of $58 \pm 43 \mathrm{Gt} \mathrm{yr}^{-1}$ from $2003-2020$ obtained using the gravity method (Wang et al., 
2021) and $90 \pm 21 \mathrm{Gt} \mathrm{yr}^{-1}$ from 2003-2019 obtained using the altimetry method (Smith et al., 2020), mass losses of $82 \pm 9$ Gt $\mathrm{yr}^{-1}$ from 1999-2009 and 51 $\pm 13 \mathrm{Gt} \mathrm{yr}^{-1}$ from 2009-2017 were estimated by Rignot et al. (2019) using the IOM.

In addition to the conflicting results obtained using the IOM and other methods, the estimates of studies based on the IOM still have significant differences due to data differences and methodological differences. The Antarctic mass balance

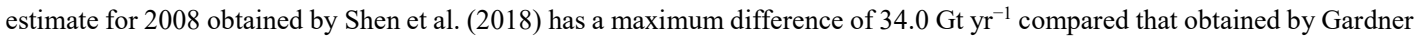
et al. (2018), and $35.1 \mathrm{Gt} \mathrm{yr}^{-1}$ compared to that obtained by Shepherd et al. (2018). Similarly, there are significant differences in the estimates based on the IOM for typical drainage basins. For example, Rignot et al. (2019), Wen et al. (2007), and Zhou et al. (2019) all estimated the MB of the Lambert (basin C-D), with a maximum difference of $5.9 \mathrm{Gt}^{-1} \mathrm{yr}^{-1}$ For Pine Island, the

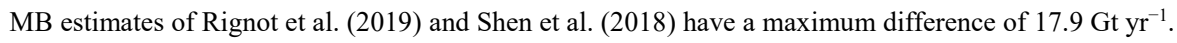

Although several studies have assessed and analyzed the data uncertainties of several parameters in detail to clarify the influence of the potential uncertainty in the IOM (Rignot et al., 2011c; Shepherd et al., 2012; Bamber et al., 2018; Gardner et al., 2018; Shen et al., 2018; Rignot et al., 2019), the dominant factors influencing the uncertainties in the MB estimation of the AIS remain unclear. For example, Rignot et al. (2019) compared the SMBs derived from the regional climate models RACMO2.3 version p1 and version p2 in selected basins. Shepherd et al. (2012) assessed the differences between the SMB of RACMO2 and in situ accumulation observations. In their second ice sheet mass balance inter-comparison exercise (IMBIE) assessment, Shepherd et al. (2018) compared the SMB products from different regional climate models and re-analysis models. These studies mainly focused on the data uncertainty of the SMB but ignored uncertainties associated with the other parameters. In addition, subtle differences in the methods used could also introduce uncertainties. The IOM is still being refined (Rignot and Thomas, 2002), so the exact calculation process varies from study to study, which has often been overlooked. The majority of previous studies have focused on the consistency between the MB estimates obtained using different methods (Rignot et al., 2011c; Shepherd et al., 2012; Shepherd et al., 2018) but have ignored the potential impact of methodological differences on the mass balance estimates.

In this study, we introduce an uncertainty analysis framework for comprehensively and systematically assessing the methodological uncertainty and data uncertainty in the MB estimation of the AIS using the IOM. By combining multi-source satellite datasets, first we quantify the uncertainties of the Antarctic MB estimate due to methodological differences, different datasets for each parameter, and data errors. Our framework enables the determination of the predominant uncertainty source and the underlying causes, as well as comparison among multiple datasets and different methods. Section 2 describes the methodology employed in this study, including the IOM and uncertainty analysis, and the data used. Section 3 presents the results corresponding to each scheme. The results are discussed in Section 4, and our conclusions are presented in Section 5. 
https://doi.org/10.5194/tc-2021-325

Preprint. Discussion started: 20 December 2021

(c) Author(s) 2021. CC BY 4.0 License.

\section{Data and Methodology}

The uncertainty in the AIS MB estimation using the IOM is divided into methodological uncertainty and data uncertainty. The methodological uncertainty arises from the methodological differences in the assessment of the MB components. The data uncertainty is mainly determined by the different datasets used and the measurement errors (i.e., measurement accuracy) due to systematic errors and random errors (i.e., measurement precision).

\subsection{Input-output method}

The IOM quantifies two individual components of the ice sheet MB in a year, i.e., the SMB (input) and ice discharge (D, output). The former, as the input component, is comprised of precipitation (snowfall or rainfall) minus surface ablation. In the absence of significant melt and when the snow sublimation and erosion are an order of magnitude smaller than the snowfall, the SMB of the ice sheet is mostly determined by the snowfall (Lenaerts et al., 2014). Because of the lack of temporally and spatially continuous in situ observations (Agosta et al., 2019), the SMB is often modeled and estimated using regional climate models (RCMs). In the calculation of the SMB, glaciers are commonly lumped into larger units for simplification, such as regions, basins, and interior sub-basins, and thus, the accuracy and consistency of the drainage boundary are crucial to the estimation.

$\mathrm{D}$ is the grounding line ice flux that is calculated as the flux gate width multiplied by the ice velocity and ice thickness. Previous estimates of D were usually presented in units of region or drainage basin, making it difficult to distinguish the dominant cause of the uncertainties associated with $\mathrm{D}$, and to determine the effects of each parameter on D. Because the ice velocity and ice thickness vary considerably at the pixel scale, we estimated D at a fine scale by discretizing the grounding line into grids of the same cell size $(1 \mathrm{~km})$ as the ice thickness and ice velocity data, which divided the MEaSUREs InSARbased grounding line into 58,597 flux gates. $\vec{D}_{i}$ at the pixel scale is calculated as follows:

$$
\vec{D}_{i}=H_{i} \cdot \vec{V}_{i} \cdot \vec{L}_{i} \cdot \rho_{\text {ice }},
$$

where $H_{i}$ is the equivalent ice thickness of flux gate $i, \vec{V}_{i}$ is the ice velocity along the ice flow direction, and $\overrightarrow{L_{i}}$ is the fluxgate width across the ice flow direction.

\subsection{Data and methods for uncertainty analysis}

The IOM parameters include the SMB, and the D parameters of ice thickness, ice velocity, grounding line, and drainage boundary. To assess the data uncertainty of these components (D and SMB) and parameters, we selected the representative 
https://doi.org/10.5194/tc-2021-325

Preprint. Discussion started: 20 December 2021

(c) Author(s) 2021. CC BY 4.0 License.

(c) (i)

Table 1. Data catalogue

\begin{tabular}{|c|c|c|c|c|}
\hline Dataset & Measuring Method & $\begin{array}{l}\text { Temporal } \\
\text { Coverage }\end{array}$ & Data format & $\begin{array}{l}\text { Data } \\
\text { Source }\end{array}$ \\
\hline SMB (RACMO2.3p1) (van Wessem et al., 2014) & ERA-Interim re-analysis & 1979-2016 & $\begin{array}{l}\text { AN: } 35 \mathrm{~km} \times 35 \mathrm{~km} \text { raster } \\
\text { AN: } 27 \mathrm{~km} \times 27 \mathrm{~km} \text { raster }\end{array}$ & KNMI \\
\hline $\begin{array}{c}\text { SMB (RACMO2.3p2) (van Wessem et al., 2016; van } \\
\text { Wessem et al., 2018) }\end{array}$ & ERA-Interim re-analysis & 1979-2016 & $\begin{array}{l}\text { AN: } 27 \mathrm{~km} \times 27 \mathrm{~km} \text { raster } \\
\text { AP: } 5.5 \mathrm{~km} \times 5.5 \mathrm{~km} \text { raster }\end{array}$ & KNMI \\
\hline Thickness (Bedmap2) (Fretwell et al., 2013) & Airborne radar altimetry & $1970-2000$ & $1 \mathrm{~km} \times 1 \mathrm{~km}$ raster & BAS \\
\hline Thickness (BedMachine V2) (Morlighem et al., 2020) & $\begin{array}{l}\text { Airborne radar altimetry; Mass } \\
\text { conservation method }\end{array}$ & 1970-2019 & $500 \mathrm{~m} \times 500 \mathrm{~m}$ raster & NASA \\
\hline Velocity (MEaSUREs) (Mouginot et al., 2012) & InSAR & 1996-2016 & $450 \mathrm{~m} \times 450 \mathrm{~m}$ raster & NASA \\
\hline Velocity (MEaSUREs) (Mouginot et al., 2019) & InSAR & 1996-2018 & $450 \mathrm{~m} \times 450 \mathrm{~m}$ raster & NASA \\
\hline Velocity (MEaSUREs) (Mouginot et al., 2017) & InSAR & 2005-2016 & $1 \mathrm{~km} \times 1 \mathrm{~km}$ raster & NASA \\
\hline Grounding line (MEaSUREs) (Rignot et al., 2013) & DInSAR & 1992-2014 & Polyline & NASA \\
\hline Drainage boundary (MEaSUREs) (Rignot et al., 2013) & InSAR & $1992-2015$ & Polygon & NASA \\
\hline
\end{tabular}

We assessed the uncertainties in the MB estimation of the AIS in three separate ways: the D and MB uncertainty due to the methodological differences; the SMB differences due to the parameterizations in different model versions and the scale effect of the products at different spatial scales; and the D uncertainty due to the uncertainties of the ice thickness, velocity, and grounding line data. The analysis framework and the data schemes used in the uncertainty assessment are presented in Table 2.

In the assessment of the methodological uncertainty in the MB, first, we assessed the possible differences between the D estimated using full velocity ranges and the $\mathrm{D}$ estimated from the high velocity region using a scaling factor. In the last four decades of MB estimations (Rignot et al., 2019), the scaling factor which was calculated over and validated on the fastest parts of the glacier, was applied to the slow-moving glacier to obtain a complete time series of the yearly D. This approach effectively fills the data gap but ignores the response of low-velocity glaciers to climate change, and it may have an unknown impact on the MB. We obtained the interannual variations in D for different ice velocity ranges by classifying D into three categories: D1

$130\left(\mathrm{~V}<20 \mathrm{~m} \mathrm{yr}^{-1}\right)$, D2 $\left(20 \mathrm{~m} \mathrm{yr}^{-1}<\mathrm{V}<100 \mathrm{~m} \mathrm{yr}^{-1}\right)$, and D3 $\left(\mathrm{V}>100 \mathrm{~m} \mathrm{yr}^{-1}\right)$. Then, we compared the D of the AIS obtained using the full velocity ranges with the D3 obtained using the scaling factor. In this study, the scaling D was estimated by applying the scaling factor of the fast flows with velocities greater than $100 \mathrm{~m} \mathrm{yr}^{-1}$ relative to their average velocity to the average D. Second, we assessed the impact of the SMB data strategy on the MB. The interannual change in the SMB for all AIS sectors is highly variable over a range of time scales. Previous studies have used different time regression methods to constrain the variability of the SMB, such as using the multi-year average SMB instead of the annual SMB for the interannual MB estimation (Shen et al., 2018). This may characterize the secular trends in the AIS mass changes, but it omits the significant temporal variability. We compared the interannual MBs obtained using the multi-year average SMB and the annual SMB for the time period 2005-2016. 
In the assessment of the SMB uncertainty due to the parameterization and scale effect, we compared the SMBs from two versions of RACMO2.3, p1 and p2 (van Wessem et al., 2014; van Wessem et al., 2018), at three different resolutions (35 km, $27 \mathrm{~km}$, and $5.5 \mathrm{~km})$. The SMB data were averaged over the period 1979-2008, except for RACMO2.3p1 (35 km), which corresponds to the 1979-2011 average. Among these, RACMO 2.3p2 (5.5 km) has the highest resolution, but only covers the Antarctic Peninsula (AP). We used the MEaSUREs Antarctic boundary dataset for the estimates in different regions and basins because this AIS boundary is consistent with the MEaSUREs grounding line.

We assessed the D response to the uncertainties of the ice thickness, velocity, and grounding line data. We used two ice thickness products, the BEDMAP2 and the BedMachine, both of which cover the AIS. The BEDMAP2 was presented in 2013 (Fretwell et al., 2013) and the BedMachine in 2020 as the latest Antarctic thickness product (Morlighem et al., 2020). For the assessment of the ice velocity uncertainty, we used two ice velocity datasets, the MEaSUREs InSAR-based velocity (Rignot et al., 2011a; Mouginot et al., 2012) and the MEaSUREs Phase-based velocity (Mouginot et al., 2019). Both provide comprehensive ice velocity maps over the past two decades and were assembled from the same multiple satellite data to cover the entire AIS. The former was generated by speckle tracking (Rignot et al., 2011a; Mouginot et al., 2012), and the latter combines interferometric phases and reaches centimeter-level precision over $80 \%$ of the AIS (Mouginot et al., 2019).

Furthermore, we assessed the D uncertainty due to errors in the ice thickness and ice velocity data. We estimated the response of the $\mathrm{D}$ uncertainties to their system error and random error based on the reference $\mathrm{D}$ calculated using the reference velocity of the MEaSUREs Phase-based velocity and the reference thickness of the BedMachine thickness. To estimate the D response to random error, we randomly generated errors in the ice thickness and ice velocity for each flux gate. The generated errors were normally distributed. Based on the precision of the data products used, we determined that the maximum random error ranges corresponding to the ice thickness and ice flow rate are $\pm 100 \mathrm{~m}$ and $\pm 20 \mathrm{~m} \mathrm{yr}^{-1}$, respectively. We made corrections for the generated random errors to avoid negative data values after introducing errors, as follows:

$$
\begin{gathered}
H_{i}^{\prime}=\left\{\begin{array}{r}
H_{i}+u_{H_{i}}, H_{i}^{\prime} \geq 0 \\
1, H_{i}^{\prime}<0
\end{array},\right. \\
V_{i}^{\prime}=\left\{\begin{array}{r}
V_{i}+u_{V_{i}}, V_{i}^{\prime} \geq 0 \\
0.1, \quad V_{i}^{\prime}<0
\end{array}\right.
\end{gathered}
$$

where $H_{i}$ and $V_{i}$ are the original ice thickness (m) and velocity $\left(\mathrm{m} \mathrm{yr}^{-1}\right)$ of flux gate $i$, respectively, $u_{H_{i}}$ is the generated random error of the thickness, $u_{V_{i}}$ is the generated random error of the velocity, $H_{i}{ }^{\prime}$ is the corrected ice thickness, and $V_{i}{ }^{\prime}$ is the corrected ice velocity. The histograms of the random errors are shown in Fig. 1. 

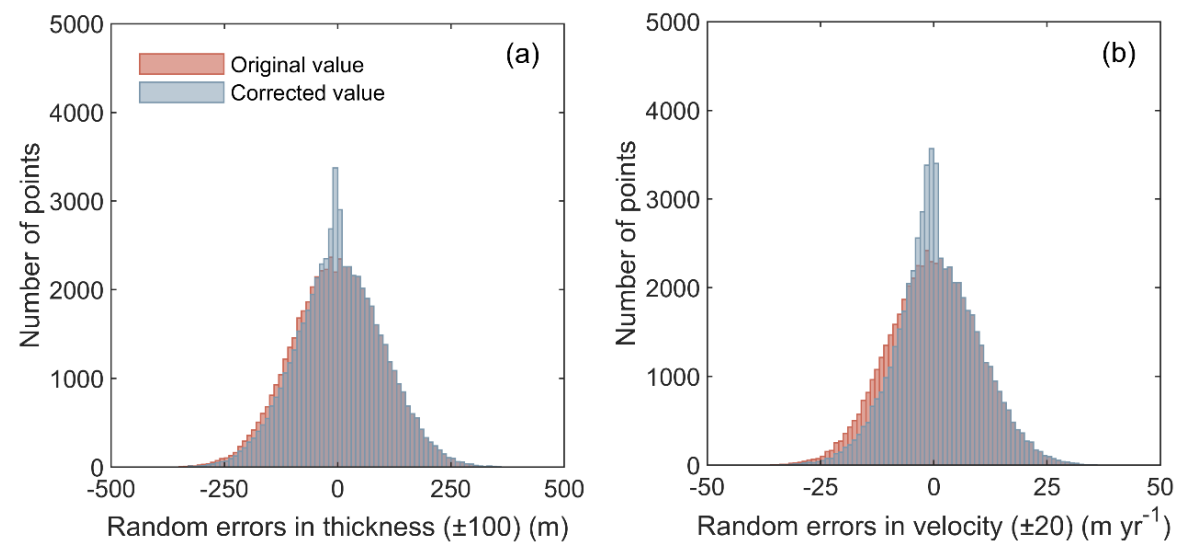

Figure 1. Histograms of the random errors in the (a) ice thickness, and (b) velocity. The orange bars are the initial normally distributed random errors and the blue bars denote the random errors corrected for negative numbers.

Finally, to investigate the D uncertainty due to the effect of the grounding line position on the D results, we generated three flux gates: the original grounding-line flux gate, the flux gate for a $1 \mathrm{~km}$ advance, and the flux gate for a $1 \mathrm{~km}$ retreat. To cover the frontal edge of the advanced ice sheet, we extended the area of the original raster dataset using the Moore-neighbor algorithm. The ice thickness and ice velocity values corresponding to the three flux gates were used to calculate their $\mathrm{D}$ value.

Table 2. Experimental schemes for uncertainty analysis of the IOM

\begin{tabular}{|c|c|c|}
\hline Component & Parameter & Data combination \\
\hline \multicolumn{3}{|c|}{ Methodological uncertainty } \\
\hline \multirow[t]{2}{*}{ MB (2005-2016) } & $\mathrm{MB}\left(\mathrm{SMB}_{\text {Annual }}\right)$ & Annual SMB (RACMO2.3p2, $27 \mathrm{~km})+\mathrm{D}_{\text {Full-range }}+\mathrm{T}_{\text {BedMachine }}+\mathrm{GL}$ \\
\hline & $\mathrm{MB}\left(\mathrm{SMB}_{\text {Average }}\right)$ & Multi-year average SMB $($ RACMO2.3p2, $27 \mathrm{~km})+,\mathrm{D}_{\text {Full-range }}+\mathrm{T}_{\text {BedMachine }}+\mathrm{GL}$ \\
\hline \multirow[t]{2}{*}{ D (2005-2016) } & $\mathrm{D}_{\text {Full-range }}$ & V(MEaSUREs Annual Velocity, 2005-2016) + $T_{\text {BedMachine }}+\mathrm{GL}$ \\
\hline & $D_{\text {scaled }}$ & V(MEaSUREs Annual Velocity, 2005-2016, applied scaling factors) $+\mathrm{T}_{\text {BedMachine }}+\mathrm{GL}$ \\
\hline \multicolumn{3}{|l|}{ Data uncertainty } \\
\hline \multirow[t]{4}{*}{ SMB } & $\mathrm{SMB}_{\mathrm{p} 1-35}$ & RACMO2.3p1, AN: $35 \mathrm{~km}$ \\
\hline & $\mathrm{SMB}_{\mathrm{p} 1-27}$ & RACMO2.3p1, AN: 27 km \\
\hline & $\mathrm{SMB}_{\mathrm{p} 2-27}$ & RACMO2.3p2, AN: $27 \mathrm{~km}$ \\
\hline & $\mathrm{SMB}_{\mathrm{p} 2-5.5}$ & RACMO2.3p2, AP: $5.5 \mathrm{~km}$ \\
\hline \multirow[t]{12}{*}{$\mathrm{D}$} & Velocity & \\
\hline & $\mathrm{D}\left(\mathrm{V}_{\text {InSAR-based }}\right)$ & V(MEaSUREs InSAR-based $)+T($ BedMachine $)+G L$ \\
\hline & $\mathrm{D}\left(\mathrm{V}_{\text {Phase-based }}\right)$ & V(MEaSUREs Phase-based $)+T($ BedMachine $)+G L$ \\
\hline & $\mathrm{D}\left(\mathrm{V}_{\text {Phase-based }}+\mathrm{e}_{\text {system }}\right)$ & $\mathrm{V}\left(\right.$ MEaSUREs Phase-based $\left.+\mathrm{e}_{\text {random }}\right)+\mathrm{T}($ BedMachine $)+\mathrm{GL}$ \\
\hline & $\mathrm{D}\left(\mathrm{V}_{\text {Phase-based }}+\mathrm{e}_{\text {random }}\right)$ & $\mathrm{V}\left(\right.$ MEaSUREs Phase-based $\left.+\mathrm{e}_{\text {system }}\right)+\mathrm{T}($ BedMachine $)+\mathrm{GL}$ \\
\hline & Thickness & \\
\hline & $\mathrm{D}\left(\mathrm{T}_{\mathrm{Bedmap} 2}\right)$ & V(MEaSUREs Phase-based $)+T($ Bedmap2) +GL \\
\hline & $\mathrm{D}\left(\mathrm{T}_{\text {BedMachine }}\right)$ & V(MEaSUREs Phase-based $)+\mathrm{T}($ BedMachine $)+\mathrm{GL}$ \\
\hline & $\mathrm{D}\left(\mathrm{T}_{\text {BedMachine }}+\mathrm{e}_{\text {system }}\right)$ & $\mathrm{V}($ MEaSUREs Phase-based $)+\mathrm{T}\left(\right.$ BedMachine $\left.+\mathrm{e}_{\text {random }}\right)+\mathrm{GL}$ \\
\hline & $\mathrm{D}\left(\mathrm{T}_{\text {BedMachine }}+\mathrm{e}_{\mathrm{random}}\right)$ & $\mathrm{V}($ MEaSUREs Phase-based $)+\mathrm{T}\left(\right.$ BedMachine $\left.+\mathrm{e}_{\text {system }}\right)+\mathrm{GL}$ \\
\hline & Grounding line & \\
\hline & $\mathrm{D}\left(\mathrm{GL}_{0}\right)$ & V(MEaSUREs Phase-based $)+\mathrm{T}($ BedMachine $)+\mathrm{GL}$ \\
\hline
\end{tabular}


https://doi.org/10.5194/tc-2021-325

Preprint. Discussion started: 20 December 2021

(c) Author(s) 2021. CC BY 4.0 License.

3 Results

3.1 Methodological uncertainty

The average annual D values of the EAIS, WAIS, APIS, islands, and the entire AIS for the time period 2005-2016 are 889.7 $\mathrm{Gt} \mathrm{yr}^{-1}, 747.5 \mathrm{Gt} \mathrm{yr}^{-1}, 161.1 \mathrm{Gt} \mathrm{yr}^{-1}, 132.2 \mathrm{Gt} \mathrm{yr}^{-1}$ and $1930.6 \mathrm{Gt} \mathrm{yr}^{-1}$, respectively, with the standard deviations of 13.9 $\mathrm{Gt} \mathrm{yr}^{-1}, 12.1 \mathrm{Gt} \mathrm{yr}^{-1}, 3.5 \mathrm{Gt} \mathrm{yr}^{-1}, 4.9 \mathrm{Gt} \mathrm{yr}^{-1}$ and $21.7 \mathrm{Gt} \mathrm{yr}^{-1}$, respectively. The average $\mathrm{D}$ for the entire AIS is $356.2 \mathrm{Gt}$ $\mathrm{yr}^{-1}$ less than that estimated by Rignot et al. (2019) for the same observation period. D1 ( V $\left.<20 \mathrm{~m} \mathrm{yr}^{-1}\right)$, D2 $(20<\mathrm{V}<100$ $\left.\mathrm{m} \mathrm{yr}^{-1}\right)$, and $\mathrm{D} 3\left(\mathrm{~V}>100 \mathrm{~m} \mathrm{yr}^{-1}\right)$ account for $1.9 \%, 11.4 \%$, and $86.7 \%$ of the average annual $\mathrm{D}$ value for the AIS, respectively. The interannual variations in $\mathrm{D}$ for the different velocity ranges are obviously inconsistent, and the interannual variation trends noted for D2 and D3 are opposite in some periods (Fig. 2a). However, since the D3 interannual variability is significantly larger than those of the other two low velocity ranges (Fig. 2a), the interannual variability of $\mathrm{D}_{\text {scaled }}$ estimated from $\mathrm{D} 3$ is only $3.6 \mathrm{Gt} \mathrm{yr}^{-1}$ greater than that of $\mathrm{D}_{\text {Full-range }}($ Fig. $2 \mathrm{~b})$. The largest difference between $\mathrm{D}_{\text {scaled }}$ and $\mathrm{D}_{\text {Full-range }}$ with a

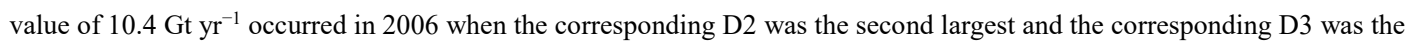
smallest.
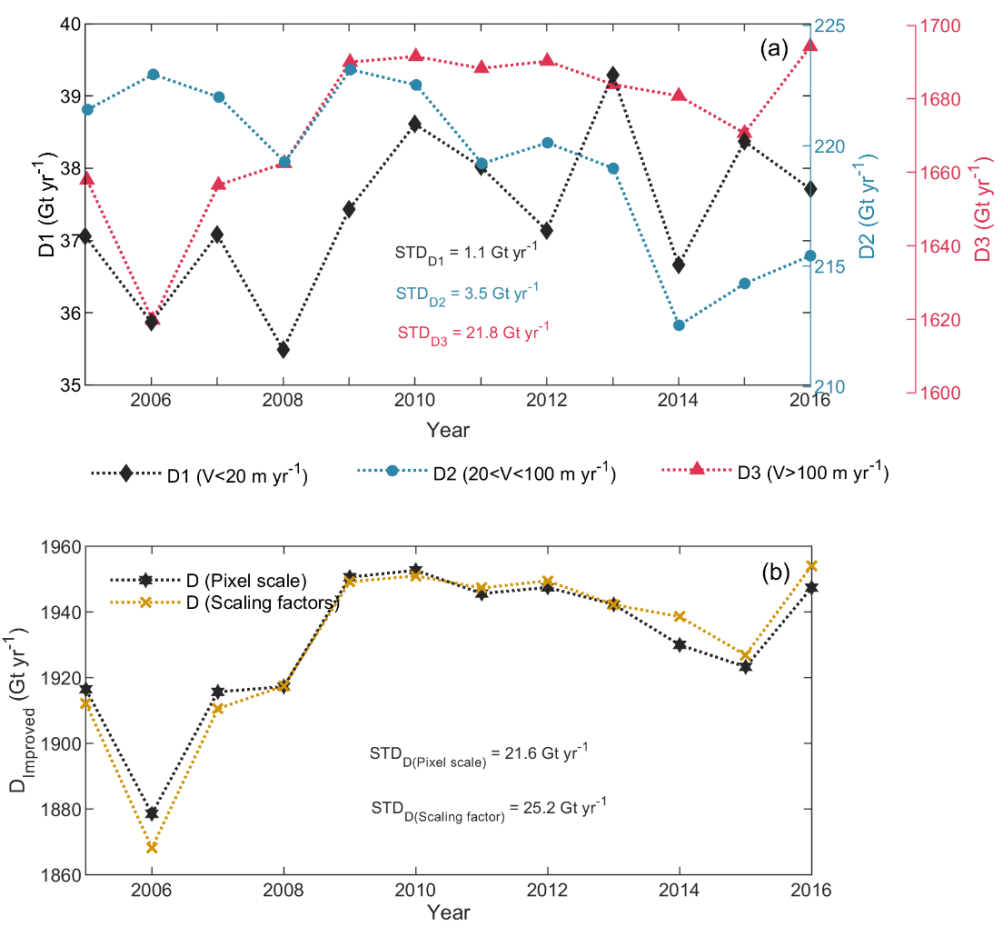
Figure 2. (a) Interannual variations in D for different velocity ranges over the period 2005-2016. D is represented by the lines of different colors and types corresponding to the axis colors, which are classified into three categories $\left(\mathrm{V}<20 \mathrm{~m} \mathrm{yr}^{-1}\right.$, $20<\mathrm{V}<100 \mathrm{~m} \mathrm{yr}^{-1}$, and $\mathrm{V}>100 \mathrm{~m} \mathrm{yr}^{-1}$ ). (b) Annual mass balance estimation of the Antarctic ice sheet from 2005 to 2016.

The lines represent the MB estimation using the refined IOM and that using scaling factors derived from the high-velocity regions.

The average annual SMBs of the EAIS, WAIS, APIS, islands and the entire AIS for the period 2005-2016 are 1163.4 Gt

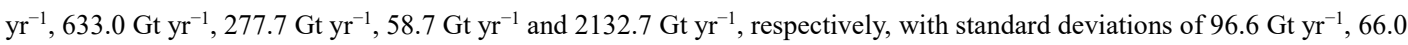

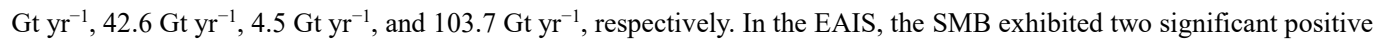
anomalies in 2009 (178.0 $\left.\mathrm{Gt} \mathrm{yr}^{-1}\right)$ and $2011\left(110.8 \mathrm{Gt} \mathrm{yr}^{-1}\right)$ compared with the 12-year mean, which were both caused by

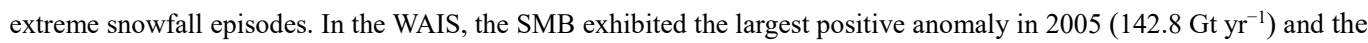

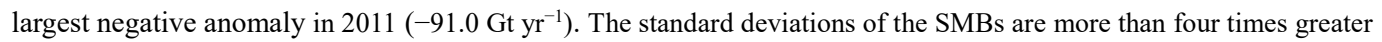
than the standard deviations of the D values for the EAIS, WAIS, and APIS regions, but the linear rate of decrease for the

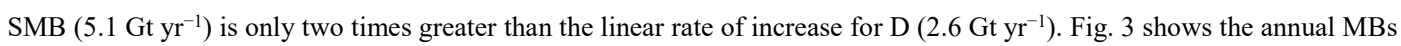
for the EAIS and WAIS obtained using the annual SMB and the average annual SMB for the period 2005-2016. The

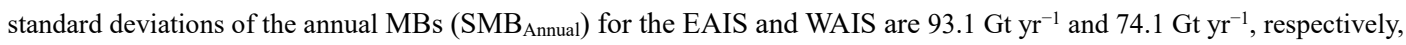
while those of the average annual $\mathrm{MBs}\left(\mathrm{SMB}_{\mathrm{Average}}\right)$ are $13.9 \mathrm{Gt} \mathrm{yr}^{-1}$ and $12.1 \mathrm{Gt} \mathrm{yr}^{-1}$, respectively. The average SMB strategy may provide the long-term trend of the $\mathrm{MB}$, but it omits the significant short-term variability, which contributes to the remarkable disagreement between the estimates.
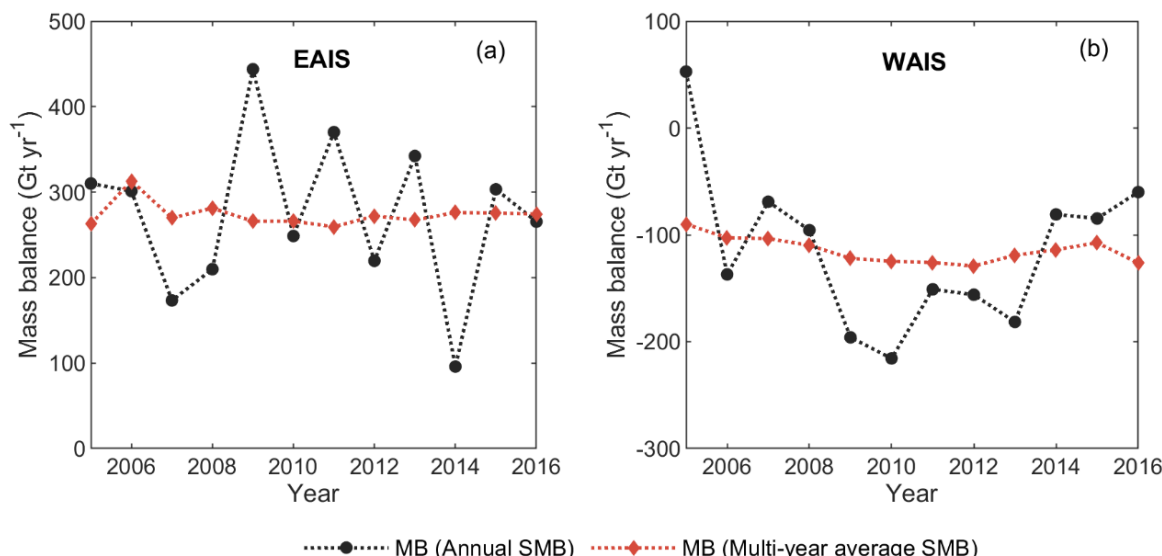

B)

MB (Multi-year average SMB)

Figure 3. Comparison of the MBs obtained using the annual SMB and average annual SMB for the period 2005-2016. 
https://doi.org/10.5194/tc-2021-325

Preprint. Discussion started: 20 December 2021

(c) Author(s) 2021. CC BY 4.0 License.

(c) (i)

3.2 Data uncertainty

\subsubsection{SMB uncertainties}

Fig. 4a shows the different SMB results from the various RCM versions and the different spatial resolutions. At the same spatial scale $(27 \mathrm{~km})$ but using parameterizations, the $\mathrm{SMB}_{\mathrm{p} 1-27}$ is $20.4 \mathrm{Gt} \mathrm{yr}^{-1}$ less than the $\mathrm{SMB}_{\mathrm{p} 2-27}$ for the entire AIS. The

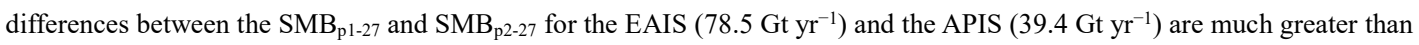
those for the islands $\left(15.6 \mathrm{Gt} \mathrm{yr}^{-1}\right.$ ) and WAIS $\left(3.1 \mathrm{Gt} \mathrm{yr}^{-1}\right)$ (Table 3). For the EAIS, the $\mathrm{SMB}_{\mathrm{pl-27}}$ and $\mathrm{SMB}_{\mathrm{p} 2-27}$ in basins with relatively large SMBs (i.e., basin C-C' (23.1 Gt yr $\left.{ }^{-1}\right)$, basin $\mathrm{C}^{\prime}-\mathrm{D}\left(15.4 \mathrm{Gt} \mathrm{yr}^{-1}\right)$, and basin D-D' $\left.\left(8.6 \mathrm{Gt} \mathrm{yr}^{-1}\right)\right)$ have relatively

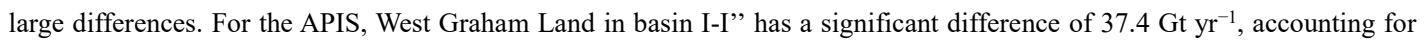
$95 \%$ of the entire APIS difference.

Table 3. Data uncertainties of the IOM $\left({\left.\mathrm{Gt} \mathrm{yr}^{-1}\right)}^{-1}\right.$

\begin{tabular}{|c|c|c|c|c|c|}
\hline Components & EAIS & WAIS & APIS & Islands & AIS \\
\hline \multicolumn{6}{|l|}{ SMB } \\
\hline $\mathrm{SMB}_{\mathrm{p} 1-35}$ & 1048.9 & 601.0 & 173.6 & 57.4 & 1880.9 \\
\hline $\mathrm{SMB}_{\mathrm{p} 1-27}$ & 1075.0 & 652.6 & 293.0 & 77.0 & 2097.6 \\
\hline $\mathrm{SMB}_{\mathrm{p} 2-27}$ & 1153.5 & 649.5 & 253.6 & 61.4 & 2118.0 \\
\hline $\mathrm{SMB}_{\mathrm{p} 2-5.5}$ & - & - & 305.3 & - & - \\
\hline ABS(dif_max) & 104.6 & 51.6 & 131.7 & 19.6 & 237.1 \\
\hline \multicolumn{6}{|l|}{ D (Ice velocity) } \\
\hline $\mathrm{D}\left(\mathrm{V}_{\text {InSAR-based }}\right)$ & 903.5 & 752.8 & 162.8 & 133.9 & 1953.1 \\
\hline $\mathrm{D}\left(\mathrm{V}_{\text {Phase-based }}\right)$ & 895.8 & 750.2 & 157.7 & 132.4 & 1936.0 \\
\hline ABS(dif_max) & 7.7 & 2.6 & 5.1 & 1.5 & 17.1 \\
\hline \multicolumn{6}{|l|}{ D (Ice thickness) } \\
\hline $\mathrm{D}\left(\mathrm{T}_{\mathrm{BEDMAP} 2}\right)$ & 914.2 & 783.1 & 183.4 & 157.1 & 2037.8 \\
\hline $\mathrm{D}\left(\mathrm{T}_{\text {Bedmachine }}\right)$ & 895.8 & 750.2 & 157.7 & 132.4 & 1936.0 \\
\hline ABS(dif_max) & 18.4 & 32.9 & 25.7 & 24.6 & 101.7 \\
\hline \multicolumn{6}{|c|}{ D (Grounding line) } \\
\hline $\mathrm{D}\left(\mathrm{GL}_{\text {Advance }}\right)$ & 798.6 & 643.1 & 113.3 & 102.9 & 1657.9 \\
\hline $\mathrm{D}\left(\mathrm{GL}_{0}\right)$ & 895.8 & 750.2 & 157.7 & 132.4 & 1936.0 \\
\hline $\mathrm{D}\left(\mathrm{GL}_{\text {Retreat }}\right)$ & 887.0 & 742.7 & 156.9 & 69.9 & 1856.4 \\
\hline ABS(dif_max) & 106.2 & 107.1 & 44.4 & 62.5 & 278.1 \\
\hline
\end{tabular}

215

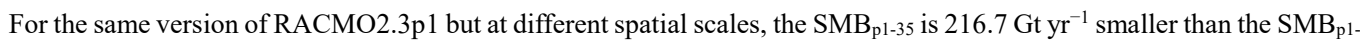
27 for the entire AIS. The APIS accounts for $55.1 \%$ of the total difference, and West Graham Land in basin I-I" accounts for $65.5 \%$ of the total difference in the APIS. Similarly, for version RACMO2.3p2 but at different spatial scales, the $\mathrm{SMB}_{\mathrm{p} 2-27}$ is 51.7 $\mathrm{Gt} \mathrm{yr}^{-1}$ less than $\mathrm{SMB}_{\mathrm{p} 2-5.5}$ for the APIS with a difference of $42.7 \mathrm{Gt} \mathrm{yr}^{-1}$ in West Graham Land, accounting for $82.6 \%$ of the difference. Fig. $4 \mathrm{~b}$ shows the distinct difference between $\mathrm{SMB}_{\mathrm{p} 2-27}$ and $\mathrm{SMB}_{\mathrm{p} 2-5.5}$ in West Graham Land over four decades,

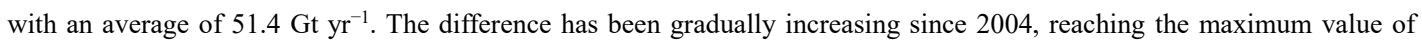
117.4 $\mathrm{Gt} \mathrm{yr}^{-1}$ in 2016 . 

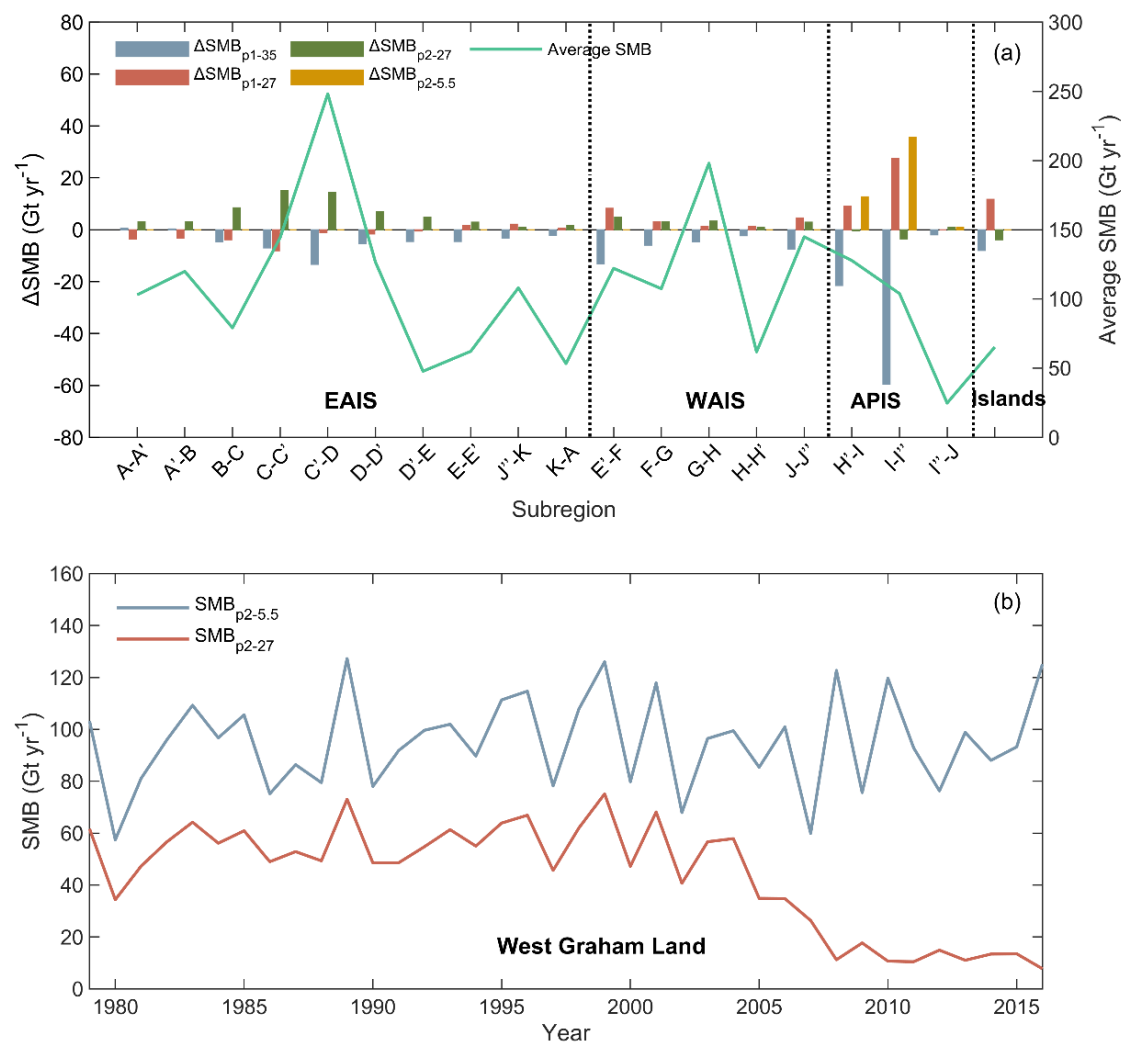

Figure 4. (a) The differences between the average SMB and the SMBs for the different RCM versions and different resolutions (colored bars, left axis). Also shown in (a) are the average SMB data (green line, right axis). (b) Comparison of the SMBs (RACMO2.3p2) at $5.5 \mathrm{~km}$ (blue line) and $27 \mathrm{~km}$ (red line) resolutions in West Graham Land, Antarctic Peninsula.

\subsubsection{Discharge response to ice velocity uncertainty}

Fig. 5 shows the uncertainty in D due to the systematic and random errors in the ice velocity based on the reference D. The D flux of the AIS increases (or decreases) by $15.1 \mathrm{Gt} \mathrm{yr}^{-1}$ with a velocity increase (or decrease) of $1 \mathrm{~m} \mathrm{yr}^{-1}$ (Fig. 5a). A random error in the ice velocity of $\pm 20 \mathrm{~m} \mathrm{yr}^{-1}$ results in a change of $41.1 \pm 0.9 \mathrm{Gt} \mathrm{yr}^{-1}$ in the $\mathrm{D}$ for the AIS, which is an order of magnitude smaller than that caused by the systematic error of the same magnitude (Fig. 5b). The change in D for the EAIS due to a random error of $\pm 20 \mathrm{~m} \mathrm{yr}^{-1}$ is the largest (17.4 $\pm 0.5 \mathrm{Gt} \mathrm{yr}^{-1}$ ), followed by the changes observedfor the WAIS (10.1 $\left.\pm 0.5 \mathrm{Gt} \mathrm{yr}^{-1}\right)$, the islands $\left(9.7 \pm 0.3 \mathrm{Gt} \mathrm{yr}^{-1}\right)$, and the APIS $\left(4.0 \pm 0.2 \mathrm{Gt} \mathrm{yr}^{-1}\right)$. 

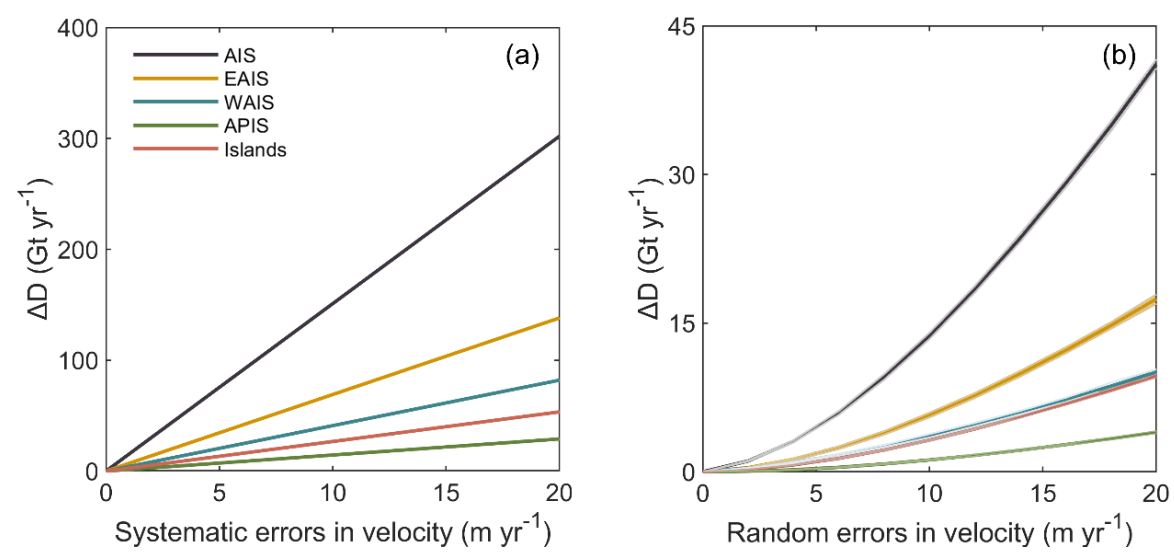

Figure 5. The D response to the systematic and random errors in velocity. The colored lines denote (a) the changes in D when the ice velocity at the grounding line increases or decreases by $0-20 \mathrm{~m}$, and (b) the changes in D caused by random errors in the velocity ranging from 0 to $20 \mathrm{~m}$. The lines are the average $\Delta$ Ds of the $100 \mathrm{x}$ estimates. The ranges of the $100 \mathrm{x}$ estimates are shaded.

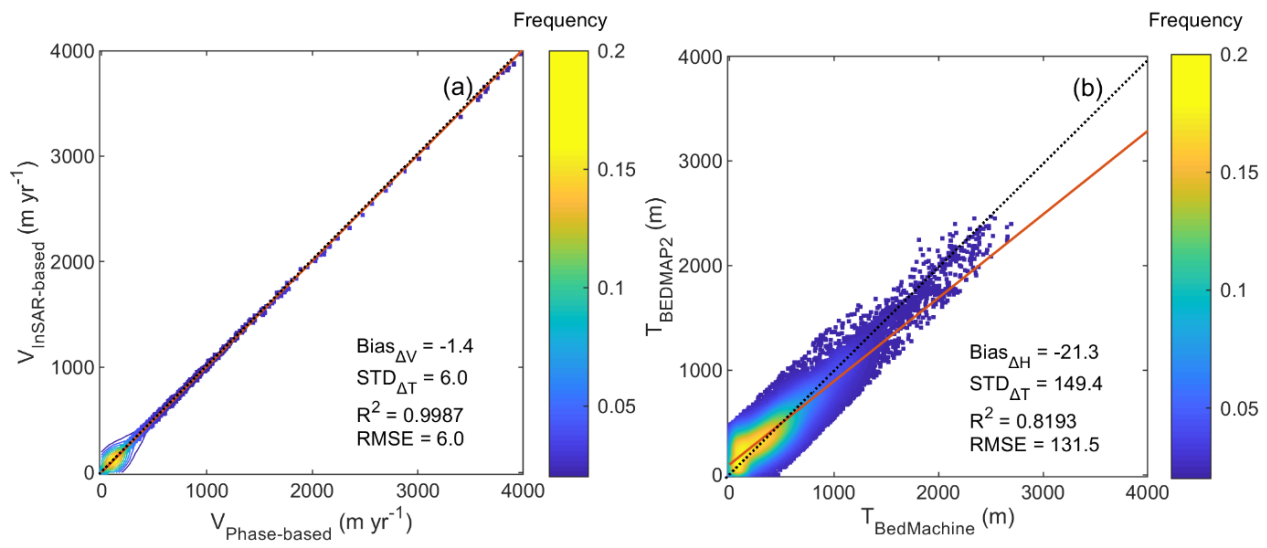

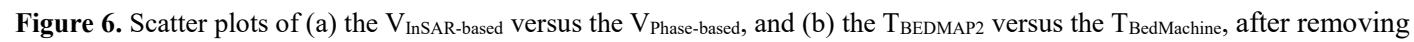
the gross errors greater than three times the standard deviation.

Using almost the same data sources, the error of the MEaSUREs Phase-based velocity is up to $20 \mathrm{~cm} \mathrm{yr}^{-1} \mathrm{over}^{8} \%$ of the Antarctic (Mouginot et al., 2019), while that of the MEaSUREs InSAR-based velocity is $1 \sim 17 \mathrm{~m} \mathrm{yr}^{-1}$ (Rignot et al., 2011a; Mouginot et al., 2012). There is an order of magnitude difference between the errors in the two velocity datasets, and thus, their difference primarily contributes to the error in the InSAR-based velocity data. The D ( $\mathrm{V}_{\text {InSAR-Based }}$ ) for the AIS is $17.1 \mathrm{Gt}$ $\mathrm{yr}^{-1}$ larger than the $\mathrm{D}$ ( $\left.\mathrm{V}_{\text {Phase-Based }}\right)$. Basin C-D in the WAIS has the largest $\Delta \mathrm{D}\left(2.0 \mathrm{Gt} \mathrm{yr}^{-1}\right)$ (Fig. 7). After removing the gross errors greater than three times the standard deviation, the velocity difference between the two is $-1.4 \pm 6.0 \mathrm{~m} \mathrm{yr}^{-1}$ (Fig. 6a), 
which corresponds to a difference in $\mathrm{D}(\Delta \mathrm{D})$ of $21.1 \mathrm{Gt} \mathrm{yr}^{-1}$ resulting from a system error of $1.4 \mathrm{~m} \mathrm{yr}^{-1}$ and a $\Delta \mathrm{D}$ of $5.9 \mathrm{Gt}$

$\mathrm{yr}^{-1}$ resulting from a random error of $6.0 \mathrm{~m} \mathrm{yr}^{-1}$ based on the above estimation. This indicates that the contribution of $\Delta \mathrm{D}$ is dominated by the system error in the ice velocity. The spatial distribution of $\Delta \mathrm{D}$ in each basin and flux gate (Fig. 7) confirms that there is a spatially consistent systematic error in the velocity. Fig. $2 b$ shows that the interannual variation in the $\mathrm{D}$ for the AIS (21.6 $\mathrm{Gt} \mathrm{yr}^{-1}$ ) estimated at the pixel scale from 2005 to 2016 is more than three times the uncertainty due to the precision (i.e., the random error) of the InSAR-based velocity, which suggests that the interannual variation in D due to the change in the ice velocity cannot be ignored.

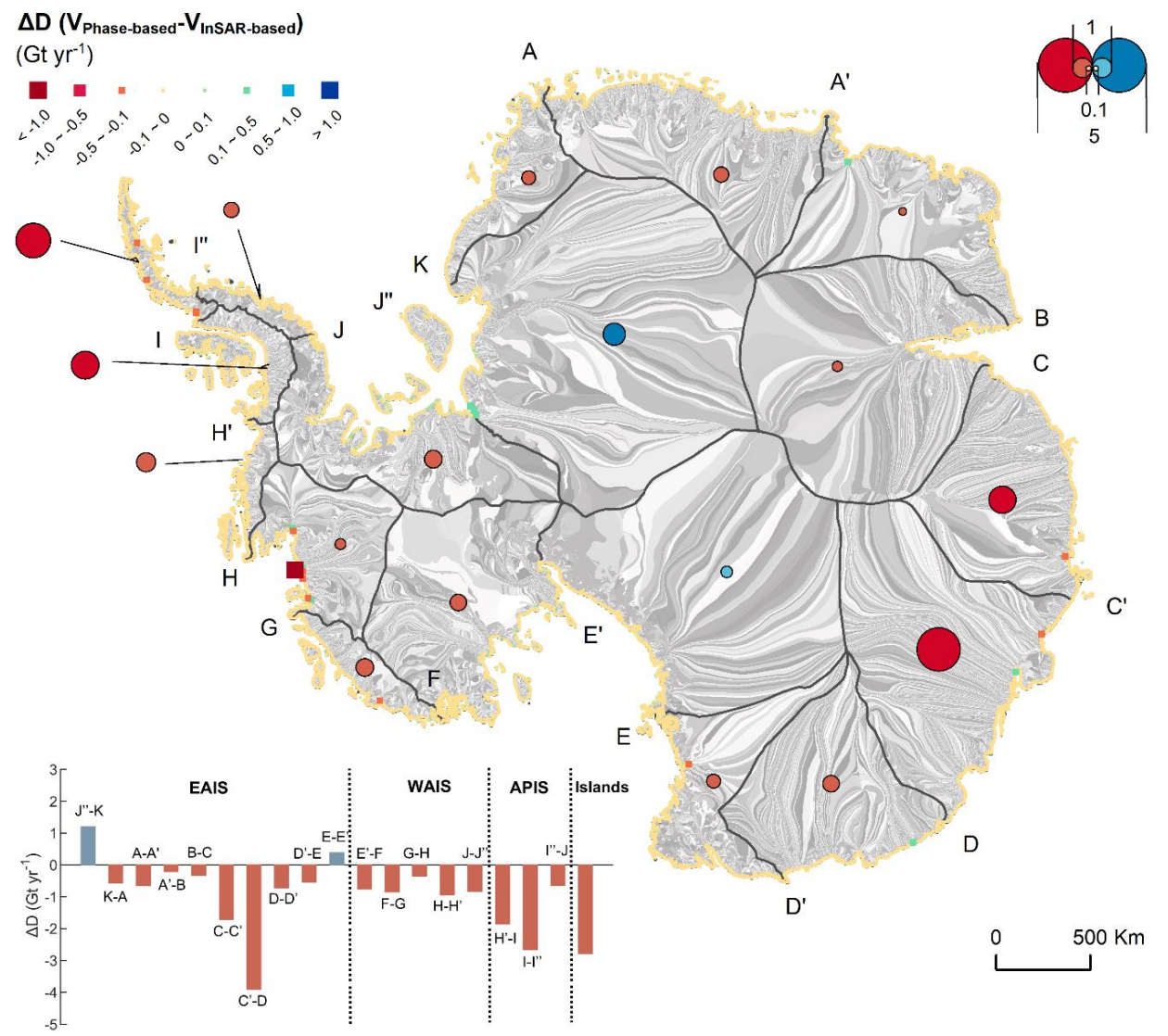

Figure 7. The $\Delta \mathrm{D}$ between the $\mathrm{D}\left(\mathrm{V}_{\text {Phase-based }}\right)$ and the $\mathrm{D}\left(\mathrm{V}_{\text {InSAR-based }}\right)$ for 18 subregions $\mathrm{A}-\mathrm{K}$ (black lines), which are colorcoded from red (negative) to blue (positive), with the circle radii proportional to the absolute differences. The bar charts below show the exact differences. The background map shows the flow units flowing into each flux unit. 


\subsubsection{Discharge response to thickness uncertainty}

Fig. 8 shows the uncertainty in D due to the systematic and random errors in the ice thickness based on the reference D. Every increase (or decrease) of $1 \mathrm{~m}$ in the ice thickness of each flux gate increases (or decreases) the D for the AIS by 3.7 Gt

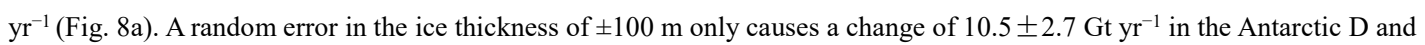
a change of less than $5 \mathrm{Gt} \mathrm{yr}^{-1}$ in the four regions (Fig. 8b). It is surprising that the islands have the largest $\Delta \mathrm{D}$ of $4.8 \pm 0.6$

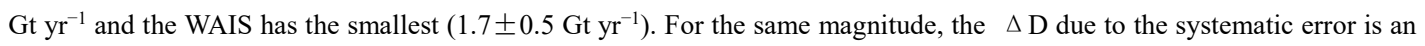
order of magnitude greater than that due to the random error.
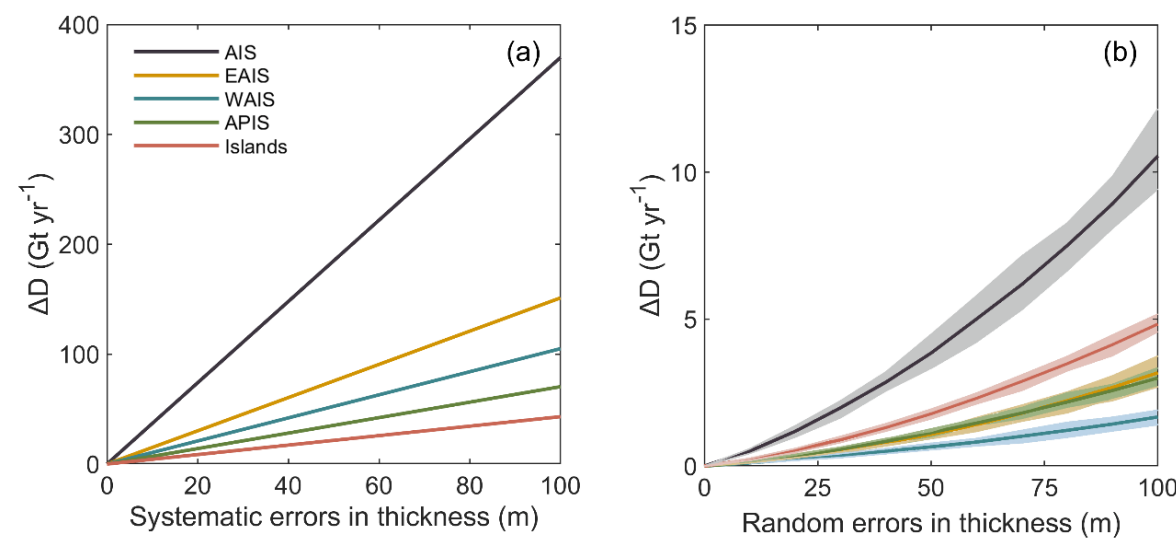

Figure 8. The response of D to the systematic and random errors in thickness. The colored lines denote (a) the changes in D when the ice thickness at the grounding line increases or decreases by $0-100 \mathrm{~m}$ and (b) the changes in D caused by random errors in thicknesses of $0-100 \mathrm{~m}$. The lines are the average $\Delta$ Ds of the $100 \mathrm{x}$ estimates. The ranges of the $100 \mathrm{x}$ estimates are shaded.

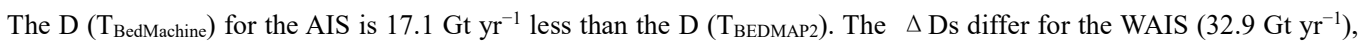
APIS (25.7 Gt $\left.\mathrm{yr}^{-1}\right)$, islands $\left(24.6 \mathrm{Gt} \mathrm{yr}^{-1}\right)$, and EAIS $\left(18.4 \mathrm{Gt} \mathrm{yr}^{-1}\right)$. The largest $\Delta \mathrm{D}$ is for basin C-D in the EAIS (41.5 Gt $\mathrm{yr}^{-1}$ ), followed by basin $\mathrm{H}-\mathrm{H}^{\prime}\left(22.9 \mathrm{Gt} \mathrm{yr}^{-1}\right)$, and basin G-H (18.9 Gt yr${ }^{-1}$ ) in the WAIS (Fig. 9). After removing the differences larger than three times the standard deviation, the thickness difference between the two datasets is $-21.3 \pm 149.4 \mathrm{~m}$ (Fig. 6b),

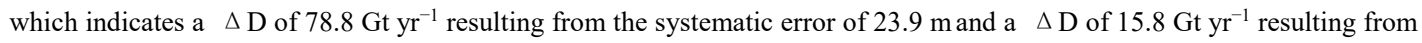

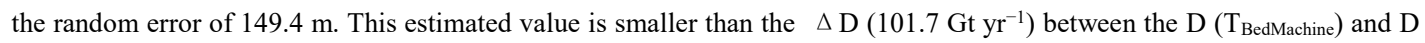
( $\left.\mathrm{T}_{\mathrm{BEDMAP} 2}\right)$ for the AIS. The basins and flux gates for which $\mathrm{D}\left(\mathrm{T}_{\mathrm{BedMachin}}\right)$ is less than $\mathrm{D}$ ( $\left.\mathrm{T}_{\mathrm{BEDMAP} 2}\right)$ are mostly located on the dominant ice-shelf thinning regions (Paolo et al., 2015), including the Amundsen Sea Bay (ASE), the Bellingshausen Sea (BS), Wilkes Land, and the West coast of the APIS (Fig. 9). The flux gates for which $\mathrm{D}$ ( $\mathrm{T}_{\text {BedMachine }}$ ) is larger than $\mathrm{D}\left(\mathrm{T}_{\mathrm{BEDMAP} 2}\right)$ are mainly located on significantly thickening large ice shelves, for example, the Ross Ice Shelf, the Ronne and Filchner Ice Shelf, and the Amery Ice Shelf. Therefore, the difference between BEDMAP2 and BedMachine is likely to include the actual thickness change. 


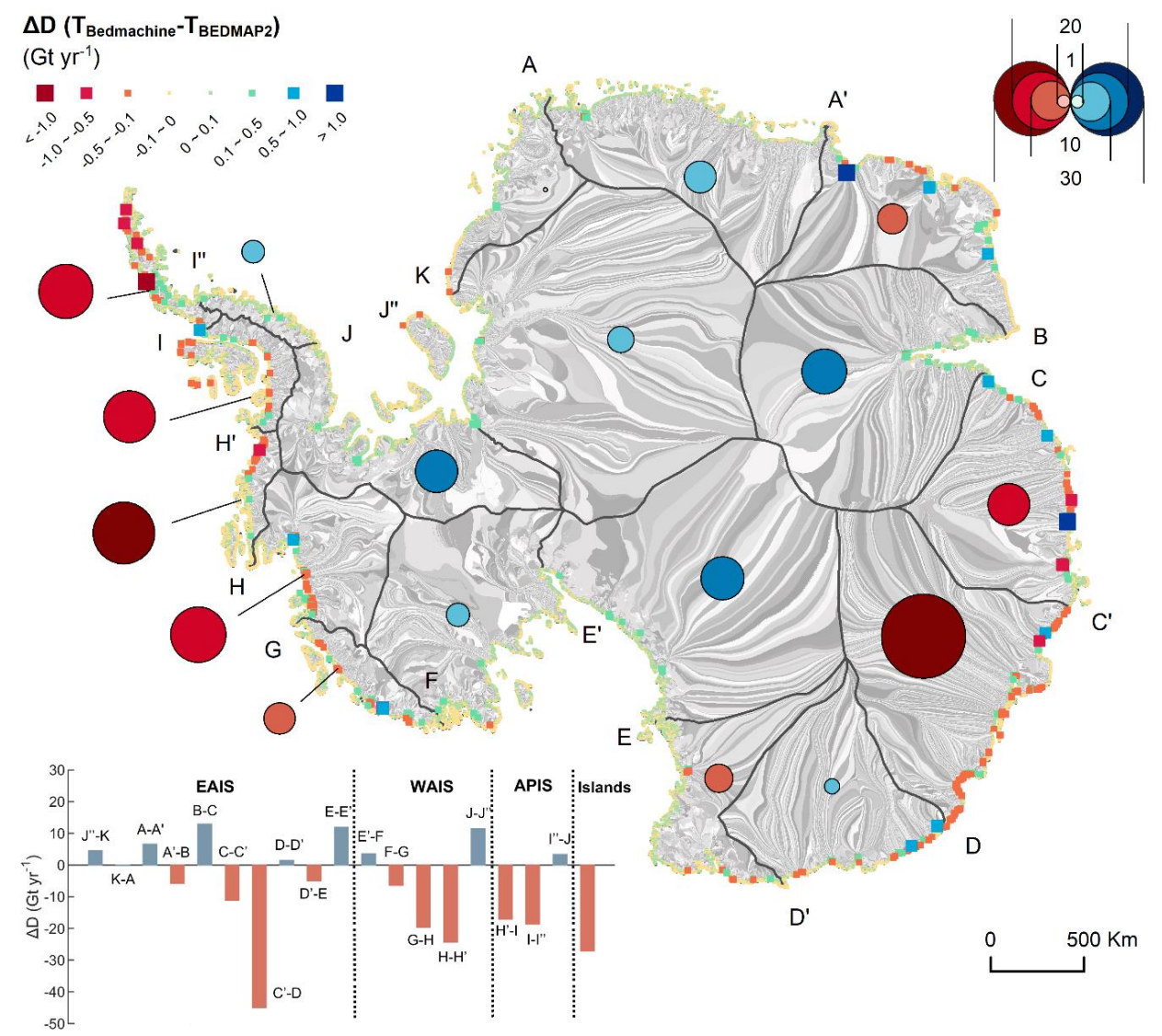

Figure 9. The $\Delta \mathrm{D}$ between the $\mathrm{D}$ ( $\left.\mathrm{T}_{\mathrm{BedMachine}}\right)$ and the $\mathrm{D}\left(\mathrm{T}_{\mathrm{BEDMAP} 2}\right)$ for 18 basins $\mathrm{A}-\mathrm{K}$ (black lines), which are color-coded from red (negative) to blue (positive), with the circle radii proportional to the absolute differences. The bar charts below show the exact differences. The background map shows the flow units flowing into each flux unit.

\subsubsection{Discharge response to grounding line uncertainty}

Compared with the $\mathrm{D}\left(\mathrm{GL}_{0}\right)$ for the AIS, the $\mathrm{D}\left(\mathrm{GL}_{\text {Advance }}\right)$ and the $\mathrm{D}\left(\mathrm{GL}_{\text {Retreat }}\right)$ decreased by $278.1 \mathrm{Gt} \mathrm{yr}^{-1}$ and $79.6 \mathrm{Gt}$ $\mathrm{yr}^{-1}$ for a $1-\mathrm{km}$ advance and a $1-\mathrm{km}$ retreat of the grounding line, respectively. Assuming a linearly distributed uncertainty, this indicates that the D uncertainty due to the precision of the $100-\mathrm{m}$ grounding line is $8.0-27.8 \mathrm{Gt} \mathrm{yr}^{-1}$, which cannot be ignored. The uncertainty due to the mis-downstream of the grounding line is several times greater than that due to the mis-upstream of the grounding line (Fig. 10).

Both the advance and retreat thicknesses (or velocities) generally exhibit systematic decreases (Fig. 10), but the estimated $\Delta \mathrm{D}$ due to a systematic decrease in the ice velocity is more than 10 times greater than that due to a systematic decrease in the thickness. The spatial distribution of the $\Delta \mathrm{D}$ due to an advance or retreat in the 99 sub-basins and 18 basins generally shows 
systematic decreases (Fig. 11), but the $\Delta \mathrm{D}$ for the advance is much greater than the $\Delta \mathrm{D}$ for the retreat. This result is consistent with the fact that there is significant basal melt of the ice-shelf near the grounding line (Rignot et al., 2013). in which the advanced grounding line downstream moves from the slow ice flow to the fast ice flow. These results indirectly verify the accuracy of the MEaSUREs grounding line.

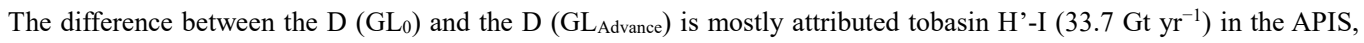
followed by basin F-G $\left(30.7 \mathrm{Gt} \mathrm{yr}^{-1}\right)$, and basin G-H (29.6 $\mathrm{Gt} \mathrm{yr}^{-1}$ ) in the WAIS (Fig. 11), which is consistent with the significant ice-shelf thinning in these regions. The $\mathrm{D}$ ( $\mathrm{GL}_{\text {Retreat }}$ ) values of the 18 basins in the EAIS, WAIS and APIS are very close to the $\mathrm{D}\left(\mathrm{GL}_{0}\right)$ values, with a total $\Delta \mathrm{D}$ of $17.1 \mathrm{Gt} \mathrm{yr}^{-1}$, but the $\mathrm{D}\left(\mathrm{GL}_{\text {Retreat }}\right)$ differs from the $\mathrm{D}\left(\mathrm{GL}_{0}\right)$ by up to $62.5 \mathrm{Gt}$ $\mathrm{yr}^{-1}$ in the islands (Fig. 11). The D (GLetreat) of $66.9 \mathrm{Gt} \mathrm{yr}^{-1}$ is closer to the $\mathrm{D}$ of $77.0 \mathrm{Gt} \mathrm{yr}^{-1}$ estimated by Rignot et al. (2019) and the average SMBs in the islands than the $\mathrm{D}\left(\mathrm{GL}_{0}\right)$, which indicates that the real grounding line of the island is likely to be upstream of the MEaSUREs grounding line.
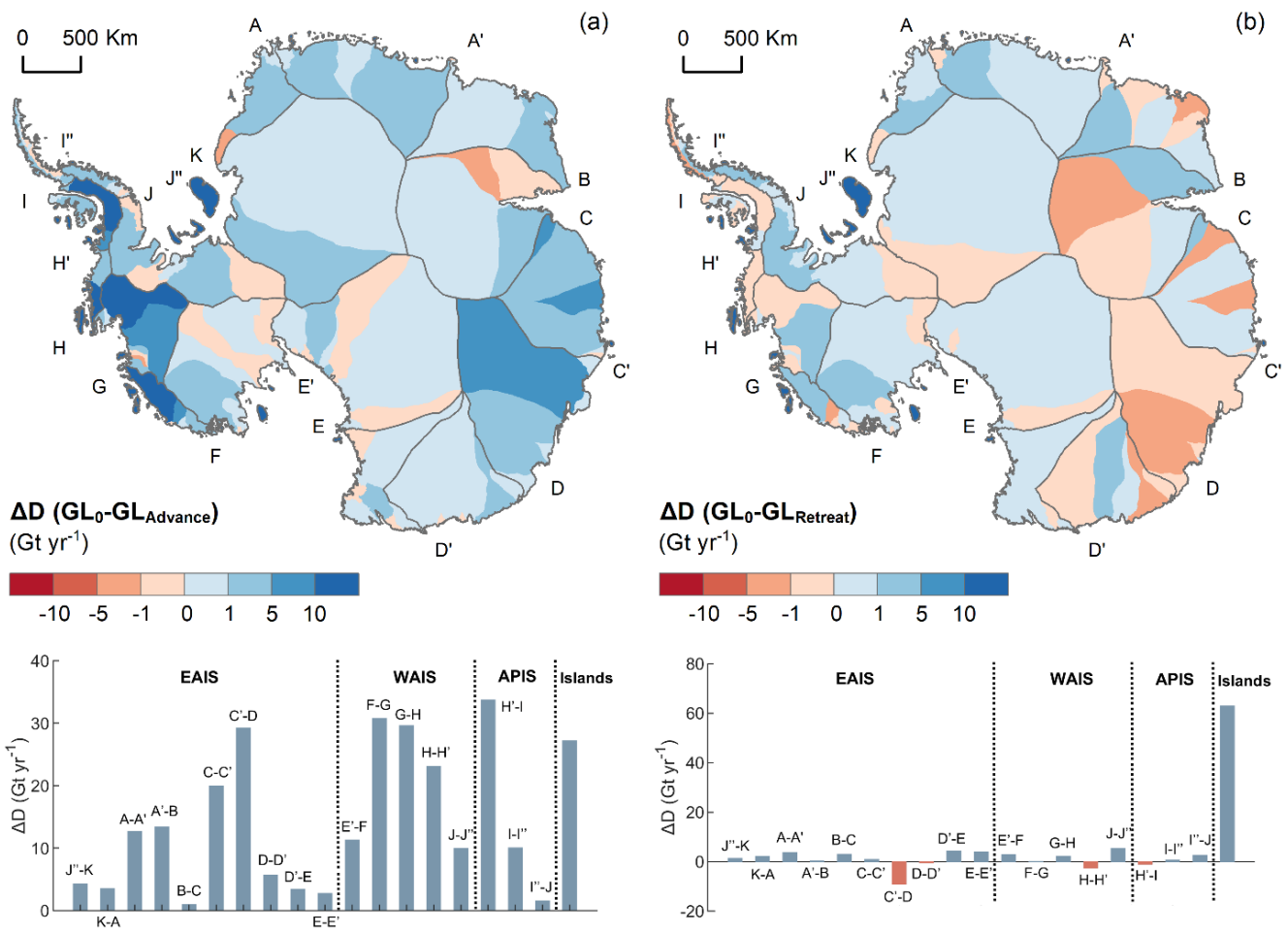

Figure 10. (a) Difference between $\mathrm{D}\left(\mathrm{GL}_{0}\right)$ and $\mathrm{D}$ (GL $\left.\mathrm{GL}_{\text {Avance }}\right)$. (b) Difference between $\mathrm{D}\left(\mathrm{GL}_{0}\right)$ and $\mathrm{D}$ (GLRetreat) for the 18 sub-regions A-K (black lines), which are color-coded from red (negative) to blue (positive). The bar charts below show the exact differences. 

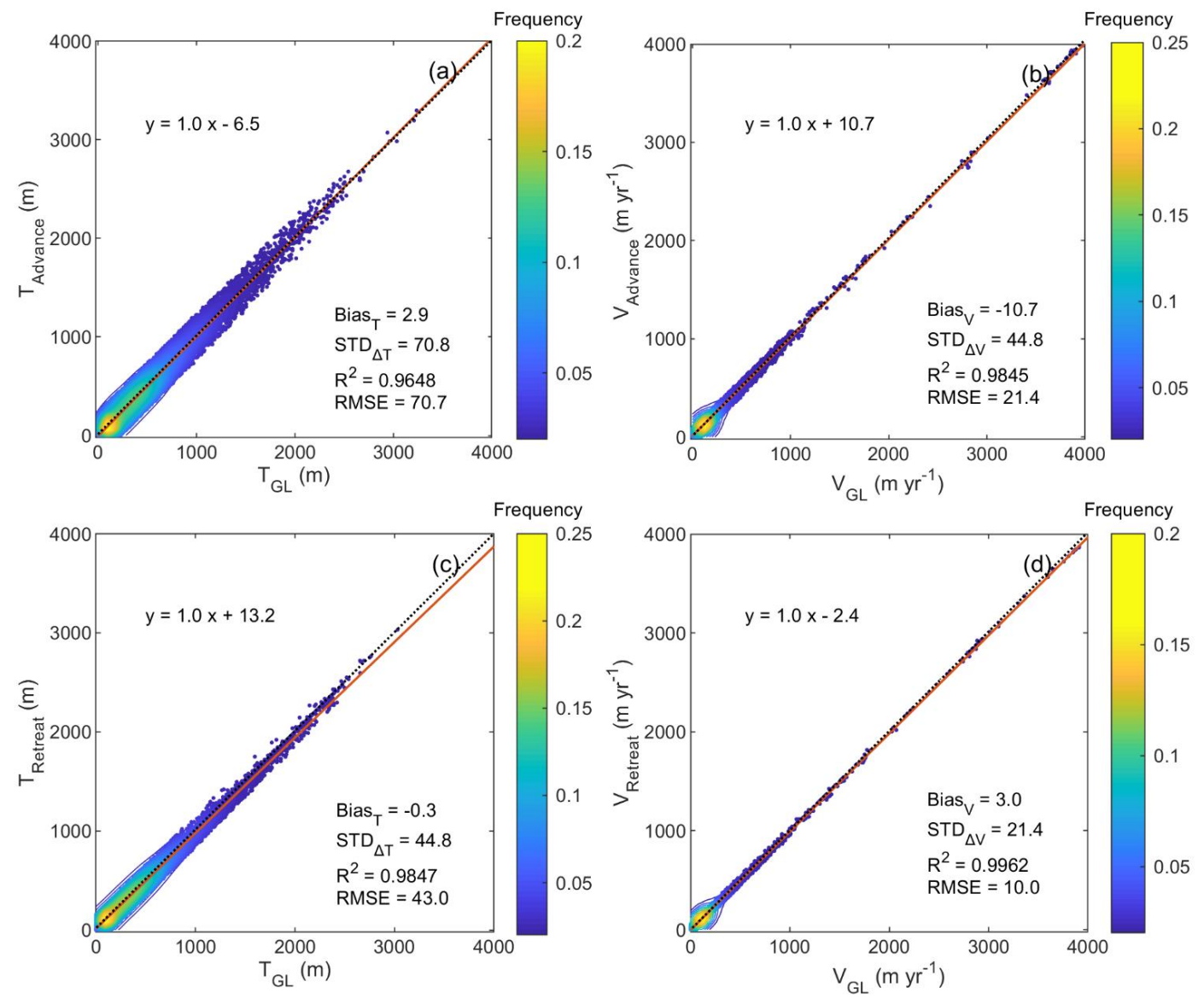

Figure 11. Scatter plots of (a) $T_{G L 0}$ versus $T_{\text {Advance, (b) }} V_{G L 0}$ versus $V_{\text {Advance, }}$ (c) $T_{G L 0}$ versus $T_{\text {Retreat, }}$, and (d) $V_{\text {GLo }}$ versus $V_{\text {Retreat, }}$ after removing the gross errors greater than three times the standard deviation.

\section{Discussion}

How much will the global and regional sea level rise over the next decade and beyond? What will be the role of the ice sheets and ocean heat storage? To answer these scientific questions, scientists are required to determine the changes in the total ice sheet MB within $15 \mathrm{Gt} \mathrm{yr}^{-1}$ over the course of a decade, as well as the changes in the SMB and D with the same accuracy over all of the ice sheets (Board et al., 2019).

Effectively quantifying the changes in the MB estimation at a fine spatiotemporal scale is the basis for presenting the spatiotemporal complexities of the ice sheet's evolution and reducing the uncertainties in the projection of future changes. In this study, we estimated the ice discharge using the refined IOM, which enables a detailed discharge estimation at the pixel scale, and we compared the results with those obtained using scaling factors. Previous studies using the IOM for Antarctic MB estimation usually simplified or overlooked the accurate estimation of D in the low-velocity regions (Gardner et al., 2018; 
Shen et al., 2018; Rignot et al., 2019). For example, Rignot et al. (2019) used a scaling factor to estimate the interannual change in $\mathrm{D}$ in the low-velocity regions under the assumption that the ice discharges of low-velocity regions and high-velocity regions have a consistent response to climate change. Our estimations of $\mathrm{D}$ for the full velocity range demonstrate that the interannual variation characteristics of the regions with different velocities are not consistent (Fig. 2), which may indicate their different responses to climate change. The estimation of $\mathrm{D}$ using a scaling factor has larger interannual variability than that of the $\mathrm{D}$ obtained using the full velocity range, that is, the refined IOM can reduce the uncertainty of the estimation. In addition, the refined IOM can facilitate comparisons among different studies, which enables the identification of which of the three parameters is the dominant contributor to the difference in $\mathrm{D}$ in any regional unit. Based on this, we assessed the methodological and data uncertainties in the MB estimation of the AIS using the IOM. Our results provide an important basis for future MB estimations with the goal of uncovering how the uncertainties can be reduced. However, the interannual variability in the $\mathrm{D}$ of high-velocity regions $\left(\mathrm{V}>100 \mathrm{~m} \mathrm{yr}^{-1}\right)$ is more than six times larger than that in low-velocity regions $(\mathrm{V}$ $<100 \mathrm{~m} \mathrm{yr}^{-1}$ ). Using the scaling factor to estimate the $\mathrm{D}$ in high-velocity regions leads to a small variability difference in $\mathrm{D}$ of

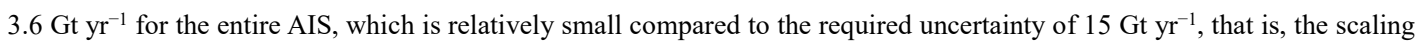
factor strategy is acceptable when there are data gaps in the low-velocity regions.

In previous studies, especially for decadal MB estimations, the annual average or linearly fitted SMB was used by default instead of the annual SMB for the annual MB estimation (Gardner et al., 2018; Shen et al., 2018; Rignot et al., 2019). The annual SMB data are probably closer to the real values, and the future change is dominated by short-term, regional snowfall events (Ligtenberg et al., 2013). For example, during the observation period 2003-2020, over 50\% of the mass gained in the EAIS occurred in only two extreme snowfall episodes between 2009 and 2012 (Wang et al., 2021). However, for the decadal MB estimation, the annual SMB affected by the short-term variability could obscure the long-term, secular trends in the SMB change. It is critical to constrain the variability of the observed rate of annual surface mass change for projecting the contribution of the ice sheet to sea-level rise (Rignot et al., 2011c; Wang et al., 2021).

The uncertainty in the SMB, i.e., the input component, is one of the dominant sources of uncertainty in the IOM. Different techniques are used to measure the SMB, including in-situ observations, satellite observations, reanalysis data, and modeling simulations. SMBs produced by regional climate models (RCMs) are commonly used in the MB estimation of the AIS. These RCMs include RACMO2.3, MAR, and SEMIC, and their related reanalysis datasets include JRA-55, MERRA, and ERAInterim (Wang et al., 2016; Fettweis et al., 2013; Krapp et al., 2017). The uncertainty of the modeled SMB depends on the model's resolution, the physical parameterization, and the forcing fields (Agosta et al., 2019). Among the RCMs, the RACMO2.3 is the most widely used SMB data source for the IOM in recent years.

Different spatial resolutions can lead to regional differences in RACMO2.3 SMB results (Shepherd et al., 2018). The

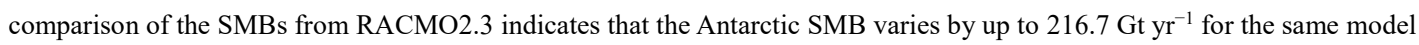
version but for different spatial resolutions (Fig. 4a, Table 4), with the greatest discrepancies occurring on the APIS, particularly 
in West Graham Land. The 5.5-km SMB probably better reflects the actual situation of the sharp climate gradients and steep mountainous topography of the Antarctic Peninsula (Lenaerts et al., 2014; van Wessem et al., 2016), especially the narrow and elongated shape of West Graham Land (Fig. 4b), which is more sensitive to scaling effects (Quattrochi and Goodchild, 1997; Marceau and Hay, 1999). Currently, the SMB of the RACMO2.3p2 (5.5 km) only covers the Antarctic Peninsula region. In some coastal regions, which are smaller in size and are subject to intense climate changes, high spatial resolution SMB products are expected to reduce the uncertainty in the MB.

The model's physical parameterization also significantly influenced the SMBs. Compared to the RACMO2.3p1, the RACMO2.3p2 has been updated to include modified snow properties and tuned cloud scheme parameters to increase precipitation towards the interior of the AIS (van Wessem et al., 2014; van Wessem et al., 2018). The RACMO2.3p1 SMBs of the basins in the EAIS are systematically smaller than the RACMO2.3p2 SMBs (Fig. 4a). It is likely that the RACMO2.3p1 systematically underestimates the snowfall, and hence, the SMB over the East Antarctic plateau. However, this scheme is controversial. Rignot et al. (2019) suggested that the RACMO2.3p1 SMB of the EAIS is in better agreement with the in-situ observations, but their MB estimation indicates that the EAIS has experienced long-term mass loss, which is diametrically opposite to the MB results obtained using the altimetry, gravity, and reconciled methods (Bamber et al., 2018; Shepherd et al., 2018; Schroder et al., 2019; Wang et al., 2020).

The uncertainty in D, i.e., the output component, is jointly determined by the uncertainties of the ice velocity, ice thickness, and the grounding line. The ice velocity, ice thickness, and the grounding line datasets, cover all of Antarctica and are typically based on remote-sensing observations. The ice velocity measurement technique is relatively mature, and annual ice velocity measurement data are available. Using almost the same data sources, the precision of the MEaSUREs Phase-based velocity is up to $20 \mathrm{~cm} \mathrm{yr}^{-1}$ (Mouginot et al., 2019), while the MEaSUREs InSAR-based velocity has a precision of $1-17 \mathrm{~m} \mathrm{yr}^{-1}$ (Rignot et al., 2011a; Mouginot et al., 2012). Because the uncertainty of D resulting either from the random error or the system error of the Phase-based velocity of $20 \mathrm{~cm} \mathrm{yr}^{-1}$ is negligible, the difference in $\mathrm{D}(\Delta \mathrm{D})$ between them is primarily attributed to the error in the InSAR-based velocity data. The velocity difference of $-1.4 \pm 6.0 \mathrm{~m} \mathrm{yr}^{-1}$ between the two suggests that the InSAR-

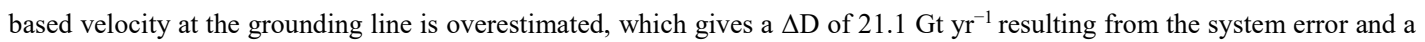

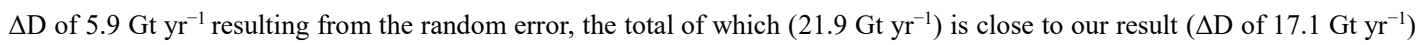
(Fig. 6b). Excluding the system error, the InSAR-based velocity product (Mouginot et al., 2017; Shen et al., 2018) also meets the uncertainty requirement (within $15 \mathrm{Gt} \mathrm{yr}^{-1}$ ). Significant changes in the ice velocity were found in previous studies for certain basins with high mass losses, such as the Thwaites Glacier, where the ice flow rate accelerated by $33 \%$ and the D increased by 75\% between 1973-1996 and 2006-2013, respectively (Mouginot et al., 2014). For an unchanged grounding line position and the same ice thickness product, the annual variation in $\mathrm{D}$ is $21.6 \mathrm{Gt} \mathrm{yr}^{-1}$, which is about three times greater than the uncertainty in D due to the random error of the InSAR-based velocity data. Thus, determining the annual variation in the ice velocity observations is necessary. 
The ice thickness is another dominant source of the uncertainty in the D estimation (Morlighem et al., 2020), due to the data gaps in the direct ice thickness measurements obtained using the RES method (Morlighem et al., 2017). The RES thickness data cover only $19 \%$ of the grounding line (Gardner et al., 2018). The thickness of the ice shelves is usually filled with indirect ice thickness estimates calculated from the surface height data assuming hydrostatic equilibrium of the ice, such as the BEDMAP2 thickness. Furthermore, the BedMachine thickness combines the radar-derived thickness with the ice motion vectors, the SMB from RACMO2.3, and the ice elevation (Morlighem et al., 2020). The ice thickness measurement errors of BEDMAP2 and BedMachine range from 30 to $1000 \mathrm{~m}$, and the average error at the grounding line is about $100 \mathrm{~m}$ (Rignot et al., 2011b; Rignot et al., 2014). However, our estimated $\Delta \mathrm{D}$ due to the difference between the BEDMAP2 and BedMachine thickness is more than 10 times greater than the $\Delta \mathrm{D}$ resulting from the random thickness error of $\pm 100 \mathrm{~m}$. It is impossible to determine if the total mean and standard deviation of the thickness difference of the $\Delta \mathrm{D}$ for the AIS is caused by the systematic error, the random error, or the combined error, which suggests regional distribution differences in the thickness. In addition, the spatial distribution of the $\Delta \mathrm{Ds}$ in the different basins is consistent with the recent changes in thickness of their connected ice shelves (Paolo et al., 2015), which suggests that the $\Delta \mathrm{D}$ probably reflects the change in the ice thickness over time.

There is a great deal of controversy regarding the selection of thickness data for the previous MB estimations using the IOM. The choice of thickness data is not limited to the BEDMAP2 and BedMachine, and there are more approaches to obtaining the ice thickness. For example, Gardner et al. (2018) back-tracked to the RES profiles upstream of the grounding line to acquire more reasonable ice thickness data. Shen et al. (2018) combined the BEDMAP2 and the RES thickness data and re-calculated the ice shelf thickness using altimetry measurements. Rignot et al. (2019) even used five types of thickness data, including the BEDMAP2, the BedMachine, the ice shelf thickness based on ERS-1 altimetry data, the ice shelf thickness obtained from a TanDEM-X (TDX) DEM, and the balance thickness. The balance thickness is derived based on the assumption

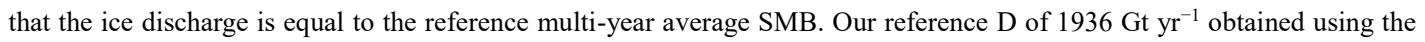
BedMachine thickness is much smaller than the average D of $2217 \mathrm{Gt} \mathrm{yr}^{-1}$ for the period 1979-2017 estimated by Rignot et al. (2019), which is mainly caused by the difference between the BedMachine thickness and the balance thickness in the EAIS and APIS. The total flux of $40 \%$ in the EAIS estimated using the balance thickness of Rignot et al. (2019) probably contributes to the significant difference between the MB in the EAIS estimated by Rignot et al. (2019) and those estimated using the altimetry, gravity, and reconciled methods (Bamber et al., 2018; Shepherd et al., 2018; Schroder et al., 2019; Wang et al., 2020).

Considering that the $\Delta \mathrm{D}$ due to the random error in the thickness of $\pm 100 \mathrm{~m}$ is only $10.5 \mathrm{Gt} \mathrm{yr}^{-1}$, filling the gaps in the RES thickness at the grounding line is the fundamental solution to constraining the uncertainty. Moreover, the $\Delta \mathrm{D}$ due to the systematic errors in the ice thickness (or the change in ice thickness) is an order of magnitude greater than that due to the random errors. In consideration of the observed thickness change near the grounding line in the WAIS and APIS (Smith et al., 2020), it is necessary to observe the annual or decadal thickness change to reduce the uncertainties in the MB estimation. 
The MEaSUREs grounding line product that we used was derived from Interferometric Synthetic Aperture Radar (InSAR) data (Rignot et al., 2013), which is considered to be the most precise method with a precision of $100 \mathrm{~m}$ (Rignot et al., 2011b; Rignot et al., 2013; Rignot et al., 2014). Our estimation of the $\Delta$ Ds corresponding to the changes in the grounding line position with this expectation suggests that the MEaSUREs grounding line on the AIS, except for the islands, is reasonable. The Antarctic grounding line is retreating, but the $1-\mathrm{km}$ retreat is equivalent to the total retreat for 40 years at the current rate of change of about $25 \mathrm{~m}$ (Konrad et al., 2018). According to our evaluation, the 1-km retreat of the current grounding line will result in a decrease in $\mathrm{D}$ of $19.9 \mathrm{Gt} \mathrm{yr}^{-1}$ on the AIS, except for the islands. Assuming that the change is linear, the annual change

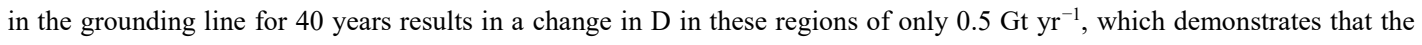
grounding line can be updated every decade or several decades compared to the other two parameters. However, the 1-km retreat in the grounding line results in a D reduction of $62.9 \mathrm{Gt} \mathrm{yr}^{-1}$ in the islands, i.e., about $50 \%$ of the original $\mathrm{D}$, which changes more significantly than the total $\Delta \mathrm{D}$ in the other regions of the AIS. Compared to the original $\mathrm{D}$, the $\mathrm{D}$ of a $1-\mathrm{km}$ retreat in the islands is closer to the balanced ice flux (equal to the multi-year average SMB) of $77.0 \mathrm{Gt} \mathrm{yr}^{-1}$ (Rignot et al., 2019). As the islands are typically surrounded by fast ice flows, the D of a 1-km advance of the grounding line in the islands may be significantly greater than the original $\mathrm{D}$ in the islands. Therefore, we believe that the true grounding line in the islands is closer to the 1-km retreat MEaSUREs grounding line. The grounding line for multiple islands from Lei et al. (2017) based on DInSAR is similarly backward compared to the MEaSUREs product, which supports this view.

\section{Conclusions}

In this study, we introduced a framework for the uncertainty analysis of the MB estimation using the IOM and assessed the method and data uncertainties in the Antarctic MB estimation. In the assessment, we present the refined D estimation at the pixel scale. The results demonstrate that it is difficult to use the previous strategies employed in various methods and the recent available data to achieve the goal of the estimation accuracy of the total ice sheet MB change to within $15 \mathrm{Gt}^{\mathrm{yr}^{-1}}$, and the total ice sheet SMB and D estimation having the same accuracy. The results of this study are as follows:

(1) The different strategies employed in the methods can contribute to considerable uncertainties in the annual MB estimation. The annual D estimated at the pixel scale, which demonstrates that the D response to climate change for ice flows with different velocities is not consistent, has a smaller interannual variability than that calculated using a scaling factor in the fastest parts of the glacier compared to the reference D. The strategy of using the yearly averaged SMB instead of the annual SMB is acceptable for decadal MB estimation to constrain variability when the long-term trend is required. However, if the research is related to short-term, regional snowfall events, it is better to use the annual SMB to determine the annual variability.

(2) The uncertainty of the modeled SMB is significantly contributed by the parameterization and scale effect. The

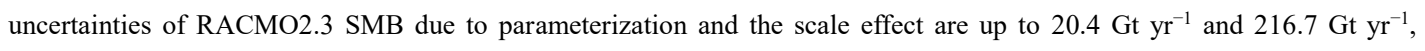


respectively. Different versions of SMB data have considerable differences in the EAIS due to the different physical process constraints adopted. Some areas of rugged terrain such as the APIS, are greatly sensitive to scale effects.

(3) The uncertainty in the future D would most likely be due to the ice thickness data rather than the ice velocity and the grounding line data. The phase-based ice velocity with decimeter-level precision meets the requirements to reach the precision goal of a high precision D estimation, but there is a lack of annual ice velocity products with the same precision. However, the InSAR-based ice velocity with a meter-level precision or ice velocity data with the same precision level, the precisions of

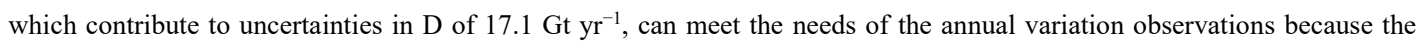
annual variation in the Antarctic $\mathrm{D}$ due to ice velocity changes is much greater than the uncertainty in $\mathrm{D}$ caused by the random error in the InSAR-based ice velocity. The InSAR-based grounding line with a $100-\mathrm{m}$ precision can be used to meet the requirements to reach this goal, which results in the D uncertainty being between 8.0-27.8 $\mathrm{Gt} \mathrm{yr}^{-1}$. However, the InSAR-based grounding line product of the islands is not likely to achieve its nominal precision. The annual variation in D due to the observed rate of change of the grounding line is much smaller than the uncertainty in $\mathrm{D}$, so it can be ignored in the annual estimation. Even ice thickness data with a $100-\mathrm{m}$ precision can be used to meet this goal, which contributes $10.5 \pm 2.7 \mathrm{Gt}^{\mathrm{yr}^{-1}}$ to the uncertainty of the D estimation. The ice thickness data gap is the dominant cause of the large uncertainty, which contributes to the $\mathrm{D}$ uncertainty of $101.7 \mathrm{Gt} \mathrm{yr}^{-1}$ and makes the reference ice thickness for Antarctica controversial. However, this data gap cannot be resolved in the short term. In addition, the annual and decadal variations in the thickness cannot be ignored.

The results of this study increase our understanding of the uncertainty sources and their effects on the estimation of the AIS MB using the IOM, and provide a systematic, comprehensive framework for uncertainty analysis of the MB estimation. In addition, they provide a scientific basis and reference for future improvements in the method and data sets.

Author Contributions. Y. Liu, Y. Lin, and Z.Y. conceived, designed, and conducted the experiment. Y. Liu and Y. Lin contributed to the research framework. Y. Lin and Y. Liu performed the data analysis. Y. Liu, Y. Lin, Z.Y., X.C., L.Z., and Q.S. contributed to the analysis of the results. All of the authors contributed to the discussion and writing of the manuscript.

Competing interests. The authors declare that they have no conflicts of interest.

Acknowledgments. We thank the National Snow and Ice Data Center (NSIDC) for providing the ice velocity, ice-sheet boundary, grounding line, and ice thickness (BedMachine) products. We thank the British Antarctic Survey (BAS) for providing the BEDMAP2, and the Royal Netherlands Meteorological Institute (KNMI) for providing the surface mass balance data. We thank LetPub (www.letpub.com) for its linguistic assistance during the preparation of this manuscript. 
Financial support. This research was supported by the National Key Research and Development Program of China (Grant

Nos. 41925027 and 41830536) and Qian Xuesen Lab. - DFH Sat. Co. Joint Research and Development Fund.

\section{References}

Agosta, C., Amory, C., Kittel, C., Orsi, A., Favier, V., Gallee, H., van den Broeke, M. R., Lenaerts, J. T. M., van Wessem, J. M., van de Berg, W. J., and Fettweis, X.: Estimation of the Antarctic surface mass balance using the regional climate model MAR (1979-2015) and identification of dominant processes, The Cryosphere, 13, 281-296, https://doi.org/10.5194/tc-13-281-2019, 2019.

Bamber, J. L., Westaway, R. M., Marzeion, B., and Wouters, B.: The land ice contribution to sea level during the satellite era, Environ. Res. Lett., 13, https://doi.org/10.1088/1748-9326/aac2f0, 2018.

Board, S. S., National Academies of Sciences, E., and Medicine: Thriving on our changing planet: A decadal strategy for Earth observation from space, The National Academies Press, Washington, USA, 2019.

Fettweis, X., Franco, B., Tedesco, M., Van Angelen, J., Lenaerts, J. T., van den Broeke, M. R., and Gallée, H.: Estimating the Greenland ice sheet surface mass balance contribution to future sea level rise using the regional atmospheric climate model MAR, The Cryosphere, 7, 469-489, https://doi.org/10.5194/tc-7-469-2013, 2013.

Forsberg, R., Sorensen, L., and Simonsen, S.: Greenland and Antarctica Ice Sheet Mass Changes and Effects on Global Sea Level, Surv. Geophys., 38, 89-104, https://doi.org/10.1007/s10712-016-9398-7, 2017.

Fretwell, P., Pritchard, H. D., Vaughan, D. G., Bamber, J. L., Barrand, N. E., Bell, R., Bianchi, C., Bingham, R. G., Blankenship, D. D., Casassa, G., Catania, G., Callens, D., Conway, H., Cook, A. J., Corr, H. F. J., Damaske, D., Damm, V., Ferraccioli, F., Forsberg, R., Fujita, S., Gim, Y., Gogineni, P., Griggs, J. A., Hindmarsh, R. C. A., Holmlund, P., Holt, J. W., Jacobel, R. W., Jenkins, A., Jokat, W., Jordan, T., King, E. C., Kohler, J., Krabill, W., Riger-Kusk, M., Langley, K. A., Leitchenkov, G., Leuschen, C., Luyendyk, B. P., Matsuoka, K., Mouginot, J., Nitsche, F. O., Nogi, Y., Nost, O. A., Popov, S. V., Rignot, E., Rippin, D. M., Rivera, A., Roberts, J., Ross, N., Siegert, M. J., Smith, A. M., Steinhage, D., Studinger, M., Sun, B., Tinto, B. K., Welch, B. C., Wilson, D., Young, D. A., Xiangbin, C., and Zirizzotti, A.: Bedmap2: improved ice bed, surface and thickness datasets for Antarctica, The Cryosphere, 7, 375-393, https://doi.org/10.5194/tc-7-375-2013, 2013.

Gardner, A. S., Moholdt, G., Scambos, T., Fahnstock, M., Ligtenberg, S., van den Broeke, M., and Nilsson, J.: Increased West Antarctic and unchanged East Antarctic ice discharge over the last 7 years, The Cryosphere, 12, 521-547, https://doi.org/10.5194/tc-12-521-2018, 2018.

Helm, V., Humbert, A., and Miller, H.: Elevation and elevation change of Greenland and Antarctica derived from CryoSat-2, The Cryosphere, 8, 1539-1559, https://doi.org/10.5194/tc-8-1539-2014, 2014.

Hugonnet, R., McNabb, R., Berthier, E., Menounos, B., Nuth, C., Girod, L., Farinotti, D., Huss, M., Dussaillant, I., and Brun, F.: Accelerated global glacier mass loss in the early twenty-first century, Nature, 592, 726-731, https://doi.org/10.1038/s41586-021-03436-z, 2021.

Kennicutt, M. C., Chown, S. L., Cassano, J. J., Liggett, D., Massom, R., Peck, L. S., Rintoul, S. R., Storey, J. W. V., Vaughan, D. G., Wilson, T. J., and Sutherland, W. J.: Polar Research: Six priorities for Antarctic science, Nature, 512, 23-25, https://doi.org/10.1038/512023a, 2014.

Konrad, H., Shepherd, A., Gilbert, L., Hogg, A. E., McMillan, M., Muir, A., and Slater, T.: Net retreat of Antarctic glacier grounding lines, Nat. Geosci., 11, 258-262, https://doi.org/10.1038/s41561-018-0082-z, 2018.

Krapp, M., Robinson, A., and Ganopolski, A.: SEMIC: an efficient surface energy and mass balance model applied to the Greenland ice sheet, The Cryosphere, 11, 1519-1535, https://doi.org/10.5194/tc-11-1519-2017, 2017.

Lei, H., Zhou, C., and Chen, Y.: Determination of grounding line on the Amery Ice Shelf using Sentinel-1 radar interferometry data, Adv. Polar Sci., 204-213, https://doi.org/10.13679/j.advps.2017.3.00204, 2017.

Lenaerts, J. T. M., van den Broeke, M. R., van Wessem, J. M., van de Berg, W. J., van Meijgaard, E., van Ulft, L. H., and 
Schaefer, M.: Extreme Precipitation and Climate Gradients in Patagonia Revealed by High-Resolution Regional Atmospheric Climate Modeling, J. Clim., 27, 4607-4621, https://doi.org/10.1175/JCLI-D-13-00579.1, 2014.

Ligtenberg, S., Van de Berg, W., Van den Broeke, M., Rae, J., and Van Meijgaard, E.: Future surface mass balance of the Antarctic ice sheet and its influence on sea level change, simulated by a regional atmospheric climate model, Clim. Dynam., 41, 867-884, https://doi.org/10.1007/s00382-013-1749-1, 2013.

Marceau, D. J., and Hay, G. J.: Remote sensing contributions to the scale issue, Canadian journal of remote sensing, 25, 357366, https://doi.org/10.1080/07038992.1999.10874735, 1999.

Massom, R., and Lubin, D.: Polar remote sensing, Springer Science \& Business Media, Chichester, UK, 2006.

McMillan, M., Shepherd, A., Sundal, A., Briggs, K., Muir, A., Ridout, A., Hogg, A., and Wingham, D.: Increased ice losses from Antarctica detected by CryoSat - 2, Geophys. Res. Lett., 41, 3899-3905, https://doi.org/10.1002/2014GL060111, 2014.

Morlighem, M., Rignot, E., Binder, T., Blankenship, D., Drews, R., Eagles, G., Eisen, O., Ferraccioli, F., Forsberg, R., Fretwell, P., Goel, V., Greenbaum, J. S., Gudmundsson, H., Guo, J. X., Helm, V., Hofstede, C., Howat, I., Humbert, A., Jokat, W., Karlsson, N. B., Lee, W. S., Matsuoka, K., Millan, R., Mouginot, J., Paden, J., Pattyn, F., Roberts, J., Rosier, S., Ruppel, A., Seroussi, H., Smith, E. C., Steinhage, D., Sun, B., van den Broeke, M. R., van Ommen, T. D., van Wessem, M., and Young, D. A.: Deep glacial troughs and stabilizing ridges unveiled beneath the margins of the Antarctic ice sheet, Nat. Geosci., 13, 132-137, https://doi.org/10.1038/s41561-019-0510-8, 2020.

Mouginot, J., Scheuchl, B., and Rignot, E.: Mapping of Ice Motion in Antarctica Using Synthetic-Aperture Radar Data, Remote Sens., 4, 2753-2767, https://doi.org/10.3390/rs4092753, 2012.

Mouginot, J., Rignot, E., and Scheuchl, B.: Sustained increase in ice discharge fromthe Amundsen Sea Embayment, West Antarctica, from 1973 to 2013, Geophys. Res. Lett., 41, 1576-1584, https://doi.org/10.1002/2013GL059069, 2014.

Mouginot, J., Rignot, E., Scheuchl, B., and Millan, R.: Comprehensive Annual Ice Sheet Velocity Mapping Using Landsat-8, Sentinel-1, and RADARSAT-2 Data, Remote. Sens., 9, 364, https://doi.org/10.3390/rs9040364, 2017.

Mouginot, J., Rignot, E., and Scheuchl, B.: Continent-Wide, Interferometric SAR Phase, Mapping of Antarctic Ice Velocity, Geophys. Res. Lett., 46, 9710-9718, https://doi.org/10.1029/2019GL083826, 2019.

Oppenheimer, M., Glavovic, B., Hinkel, J., van de Wal, R., Magnan, A. K., Abd-Elgawad, A., Cai, R., Cifuentes-Jara, M., Deconto, R. M., and Ghosh, T.: Sea level rise and implications for low lying islands, coasts and communities, in: IPCC Special Report on the Ocean and Cryosphere in a Changing Climate, edited by: Pörtner, H.-O., Roberts, D. C., MassonDelmotte, V., Zhai, P., Tignor, M., Poloczanska, E., Mintenbeck, K., Nicolai, M., Okem, A., Petzold, J., Rama, B., and Weyer, N., Cambridge University Press, Cambridge, UK, 126 pp., 2019.

Paolo, F. S., Fricker, H. A., and Padman, L.: Volume loss from Antarctic ice shelves is accelerating, Science, 348, 327-331, https://doi.org/10.1126/science.aaa0940, 2015.

Quattrochi, D. A., and Goodchild, M. F.: Scale in remote sensing and GIS, CRC press, Boca Raton, USA, 1997.

Rignot, E., and Thomas, R. H.: Mass balance of polar ice sheets, Science, 297, 1502-1506, https://doi.org/10.1126/science.1073888, 2002.

Rignot, E., Bamber, J. L., Van Den Broeke, M. R., Davis, C., Li, Y. H., Van De Berg, W. J., and Van Meijgaard, E.: Recent Antarctic ice mass loss from radar interferometry and regional climate modelling, Nat. Geosci., 1, 106-110, https://doi.org/10.1038/ngeo102, 2008.

Rignot, E., Mouginot, J., and Scheuchl, B.: Ice Flow of the Antarctic Ice Sheet, Science, 333, 1427-1430, https://doi.org/10.1126/science.1208336, 2011a.

Rignot, E., Mouginot, J., and Scheuchl, B.: Antarctic grounding line mapping from differential satellite radar interferometry, Geophys. Res. Lett., 38, https://doi.org/10.1029/2011GL047109, L10504, 2011 b.

Rignot, E., Velicogna, I., van den Broeke, M. R., Monaghan, A., and Lenaerts, J.: Acceleration of the contribution of the Greenland and Antarctic ice sheets to sea level rise, Geophys. Res. Lett., 38, L05503, https://doi.org/10.1029/2011GL046583, 2011c.

Rignot, E., Jacobs, S., Mouginot, J., and Scheuchl, B.: Ice-Shelf melting around Antarctica, Science, 341, 266-270, https://doi.org/10.1126/science.1235798, 2013. 
Rignot, E., Mouginot, J., Morlighem, M., Seroussi, H., and Scheuchl, B.: Widespread, rapid grounding line retreat of Pine Island, Thwaites, Smith, and Kohler glaciers, West Antarctica, from 1992 to 2011, Geophys. Res. Lett., 41, 3502-3509, https://doi.org/10.1002/2014GL060140, 2014.

Rignot, E., Mouginot, J., Scheuchl, B., van den Broeke, M., van Wessem, M. J., and Morlighem, M.: Four decades of Antarctic Ice Sheet mass balance from 1979-2017, Proc. Natl. Acad. Sci. U.S.A., 116, 1095-1103, https://doi.org/10.1073/pnas.1812883116, 2019.

Schroder, L., Horwath, M., Dietrich, R., Helm, V., van den Broeke, M. R., and Ligtenberg, S. R. M.: Four decades of Antarctic surface elevation changes from multi-mission satellite altimetry, The Cryosphere, 13, 427-449, https://doi.org/10.5194/tc-13-427-2019, 2019.

Shen, Q., Wang, H. S., Shum, C. K., Jiang, L. M., Hsu, H. T., and Dong, J. L.: Recent high-resolution Antarctic ice velocity maps reveal increased mass loss in Wilkes Land, East Antarctica, Sci. Rep., 8, 4477, https://doi.org/10.1038/s41598-01822765-0, 2018.

Shepherd, A., Ivins, E. R., Geruo, A., Barletta, V. R., Bentley, M. J., Bettadpur, S., Briggs, K. H., Bromwich, D. H., Forsberg, R., Galin, N., Horwath, M., Jacobs, S., Joughin, I., King, M. A., Lenaerts, J. T. M., Li, J. L., Ligtenberg, S. R. M., Luckman, A., Luthcke, S. B., McMillan, M., Meister, R., Milne, G., Mouginot, J., Muir, A., Nicolas, J. P., Paden, J., Payne, A. J., Pritchard, H., Rignot, E., Rott, H., Sorensen, L. S., Scambos, T. A., Scheuchl, B., Schrama, E. J. O., Smith, B., Sundal, A. V., van Angelen, J. H., van de Berg, W. J., van den Broeke, M. R., Vaughan, D. G., Velicogna, I., Wahr, J., Whitehouse, P. L., Wingham, D. J., Yi, D. H., Young, D., and Zwally, H. J.: A Reconciled Estimate of Ice-Sheet Mass Balance, Science, 338, 1183-1189, https://doi.org/10.1126/science.1228102, 2012.

Shepherd, A., Ivins, E., Rignot, E., Smith, B., van den Broeke, M., Velicogna, I., Whitehouse, P., Briggs, K., Joughin, I., Krinner, G., Nowicki, S., Payne, T., Scambos, T., Schlegel, N., Geruo, A., Agosta, C., Ahlstrom, A., Babonis, G., Barletta, V., Blazquez, A., Bonin, J., Csatho, B., Cullather, R., Felikson, D., Fettweis, X., Forsberg, R., Gallee, H., Gardner, A., Gilbert, L., Groh, A., Gunter, B., Hanna, E., Harig, C., Helm, V., Horvath, A., Horwath, M., Khan, S., Kjeldsen, K. K., Konrad, H., Langen, P., Lecavalier, B., Loomis, B., Luthcke, S., McMillan, M., Melini, D., Mernild, S., Mohajerani, Y., Moore, P., Mouginot, J., Moyano, G., Muir, A., Nagler, T., Nield, G., Nilsson, J., Noel, B., Otosaka, I., Pattle, M. E., Peltier, W. R., Pie, N., Rietbroek, R., Rott, H., Sandberg-Sorensen, L., Sasgen, I., Save, H., Scheuchl, B., Schrama, E., Schroder, L., Seo, K. W., Simonsen, S., Slater, T., Spada, G., Sutterley, T., Talpe, M., Tarasov, L., van de Berg, W. J., van der Wal, W., van Wessem, M., Vishwakarma, B. D., Wiese, D., Wouters, B., and Team, I.: Mass balance of the Antarctic Ice Sheet from 1992 to 2017, Nature, 558, 219-222, https://doi.org/10.1038/s41586-018-0179-y, 2018.

Smith, B., Fricker, H. A., Gardner, A. S., Medley, B., Nilsson, J., Paolo, F. S., Holschuh, N., Adusumilli, S., Brunt, K., Csatho, B., Harbeck, K., Markus, T., Neumann, T., Siegfried, M. R., and Zwally, H. J.: Pervasive ice sheet mass loss reflects competing ocean and atmosphere processes, Science, 368, 1239-1242, https://doi.org/10.1126/science.aaz5845, 2020.

Thomas, E. R., van Wessem, J. M., Roberts, J., Isaksson, E., Schlosser, E., Fudge, T. J., Vallelonga, P., Medley, B., Lenaerts, J., Bertler, N., van den Broeke, M. R., Dixon, D. A., Frezzotti, M., Stenni, B., Curran, M., and Ekaykin, A. A.: Regional Antarctic snow accumulation over the past 1000 years, Clim. Past, 13, 1491-1513, https://doi.org/10.5194/cp-13-14912017, 2017.

van Wessem, J., Ligtenberg, S., Reijmer, C., Van De Berg, W., Van Den Broeke, M., Barrand, N., Thomas, E., Turner, J., Wuite, J., and Scambos, T.: The modelled surface mass balance of the Antarctic Peninsula at $5.5 \mathrm{~km}$ horizontal resolution, The Cryosphere, 10, 271-285, https://doi.org/10.5194/tc-10-271-2016, 2016.

van Wessem, J. M., Reijmer, C. H., Morlighem, M., Mouginot, J., Rignot, E., Medley, B., Joughin, I., Wouters, B., Depoorter, M. A., Bamber, J. L., Lenaerts, J. T. M., van de Berg, W. J., van den Broeke, M. R., and van Meijgaard, E.: Improved representation of East Antarctic surface mass balance in a regional atmospheric climate model, J. Glaciol., 60, 761-770, https://doi.org/10.3189/2014JoG14J051, 2014.

van Wessem, J. M., van de Berg, W. J., Noel, B. P. Y., van Meijgaard, E., Amory, C., Birnbaum, G., Jakobs, C. L., Kruger, K., Lenaerts, J. T. M., Lhermitte, S., Ligtenberg, S. R. M., Medley, B., Reijmer, C. H., van Tricht, K., Trusel, L. D., van Ulft, L. H., Wouters, B., Wuite, J., and van den Broeke, M. R.: Modelling the climate and surface mass balance of polar ice sheets using RACMO2-Part 2: Antarctica 
Velicogna, I., Sutterley, T. C., and van den Broeke, M. R.: Regional acceleration in ice mass loss from Greenland and Antarctica using GRACE time-variable gravity data, Geophys Res Lett, 41, 8130-8137, https://doi.org/10.1002/2014GL061052, 2014.

Wadham, J. L., Hawkings, J. R., Tarasov, L., Gregoire, L. J., Spencer, R. G. M., Gutjahr, M., Ridgwell, A., and Kohfeld, K. E.: Ice sheets matter for the global carbon cycle, Nat. Commun., 10, 3567, https://doi.org/10.1038/s41467-019-11394-4, 2019.

Wang, L., Davis, J. L., and Howat, I. M.: Complex Patterns of Antarctic Ice Sheet Mass Change Resolved by Time-Dependent Rate Modeling of GRACE and GRACE Follow-On Observations, Geophys. Res. Lett., 48, e2020GL090961, https://doi.org/10.1029/2020GL090961, 2021.

Wang, Y., Ding, M., Van Wessem, J., Schlosser, E., Altnau, S., van den Broeke, M. R., Lenaerts, J. T., Thomas, E. R., Isaksson, E., and Wang, J.: A comparison of Antarctic Ice Sheet surface mass balance from atmospheric climate models and in situ observations, J. Climate, 29, 5317-5337, https://doi.org/10.1175/JCLI-D-15-0642.1, 2016.

Wen, J. H., Jezek, K. C., Csatho, B. M., Herzfeld, U. C., Farness, K. L., and Huybrechts, P.: Mass budgets of the Lambert, Mellor and Fisher Glaciers and basal fluxes beneath their flowbands on Amery Ice Shelf, Sci. China Ser. D, 50, 1693-1706, https://doi.org/10.1007/s11430-007-0120-y, 2007.

Zhou, C. X., Liang, Q., Chen, Y. M., Lei, H. B., Fu, Z., Zheng, L., and Liu, R. X.: Mass Balance Assessment of the Amery Ice Shelf Basin, East Antarctica, Earth Space Sci., 6, 1987-1999, https://doi.org/10.1029/2019EA000596, 2019.

Zwally, H. J., Li, J., Robbins, J. W., Saba, J. L., Yi, D. H., and Brenner, A. C.: Mass gains of the Antarctic ice sheet exceed losses, J. Glaciol., 61, 1019-1036, https://doi.org/10.3189/2015JoG15J071, 2015. 